\title{
O VELHO E
}

O NOVO

\section{NA ARQUEOLOGIA}

\section{AMAZÔNICA}

EDUARDO GÓES

NEVES

Museu de Arqueologia

e Etnologia

Universidade de São

Paulo

E-mail:edgneves@usp.br 


\section{INTRODUÇÃO}

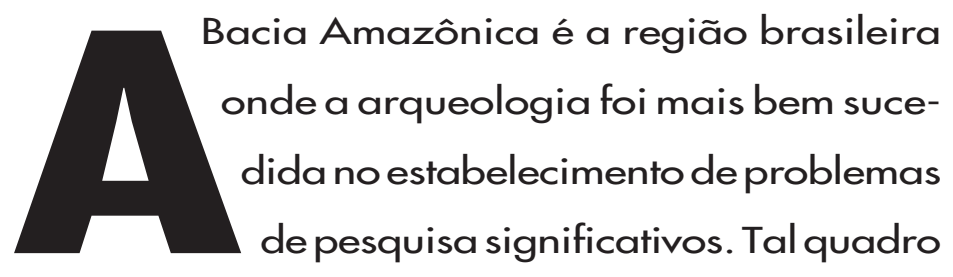

deve-se ao fato de que há, na Amazônia, uma tradição de meio século de pesquisas orientadas a partir de questões antropológicas gerais que demandam tratamentos arqueológicos e etnográficos. Não foi esse o caso em outras partes do Brasil, onde a arqueologia permaneceu, em linhas gerais, um empreendimento descritivo sem maiores preocupações históricas ou antropológicas.

Os problemas de pesquisa estabelecidos pela arqueologia amazônica são tanto teóricos como metodológicos, tendo implicações diretas para os tipos de reconstituição feitos sobre o passado précolonial da região, bem como para outras áreas das terras baixas da América do Sul. Embora profundamente relacionados, esses problemas podem se agrupar em três categorias gerais.

Primeiramente há a investigação da inter-relação entre variáveis ambientais e processos sociais e culturais. Pesquisas sobre esse tema na Amazônia remontam à década de 40 , inicialmente sob uma forte influência da ecologia cultural norte-americana e do determinismo ecológico, mas atualmente com evidências crescentes para uma crítica de tais premissas deterministas. Essa perspectiva crítica deve ser entendida como parte de um processo geral de revisão, historicamente orientado, da antropologia ecológica, às vezes chamado de ecologia histórica 
(Balée 1995). Frente aos problemas relacionados à ocupação caótica de partes da Bacia Amazônica, os resultados de pesquisa feitos com esse foco podem ter consequiências políticas importantes.

Em segundo lugar há o estabelecimento de fronteiras étnicas - particularmente lingüísticas - no passado através de vestígios arqueológicos, principalmente a cerâmica. Este nãoé um problema exclusivo da arqueologia amazônica sendo, por exemplo, um tema fundamental da arqueologia na Polinésia (Kirch e Green 1987). No caso das terras baixas da América do Sul, no entanto, vários modelos apresentados para explicar os padrões contemporâneos de distribuição das línguas indígenas têm suposições explícitas ou implícitas sobre o registro arqueológico da Amazônia. Isso porque nas terras baixas da América do Sul a identificação lingüística serve freqüentemente como identificação étnica, uma tendência que remonta, no Brasil, às pesquisas feitas porvon Martius no século XIX (von Martius 1982).

Finalmente, há a avaliação do impacto da conquista européia sobre os padrões pré-coloniais de organização social e política na Amazônia. Tal problema é pertinente para toda a antropologia do continente americano, mas verifica-se mais uma vez que, na arqueologia brasileira, apenas na Amazônia ele foi incorporado à agenda de pesquisas. Nesse caso, a avaliação do impacto da conquista envolve várias perguntas metodológicas não solucionadas que variam desde diferentes perspectivas sobre pesquisas de campo a diferentes posturas quanto ao uso de analogias etnográficas.

Graças a esta situação, a arqueologia amazônica é tratada normalmente como um campo diferenciado nas sínteses de arqueologia brasileira. Esse é o caso, por exemplo, de Arqueologia Brasileira (Prous 1992), a mais completa e melhor obra disponível sobre o tema. Como explicar esse quadro diferenciado? Parte da resposta é histórica: apesar da importância de pesquisas localizadas feitas em outros locais, notadamente as pesquisas de Lund em
Minas Gerais, a arqueologia brasileira nasceu praticamente na Amazônia, durante a segunda metade do século XIX (Barreto 1992; Prous 1992; Mendonça de Souza 1991). Assim, já na década de 70 do século XIX, as primeiras sínteses de arqueologia brasileira apresentavam discussões prolongadas sobre o registro arqueológico amazônico (Netto 1885). Na década de 80 do mesmo século, monografias inteiras foram escritas com foco em problemas de arqueologia amazônica (Hartt 1885; Barbosa Rodrigues 1888). Os esforços de pesquisa destes e de outros pioneiros culminaram já no século XX, com a breve porém relevante síntese de Nordenskiöld (1930), baseada em grande parte nos trabalhos de campo realizados por Curt Nimuendajú no baixo Amazonas (Linné 1928).

A essa precedência histórica, deve-se acrescentar a importância dos trabalhos de Julian Steward e seus colaboradores no Handbook of South American Indians. O trabalho de Steward no Handbook foi importante porque estabeleceu modelos baseados em premissas ecológicas para a arqueologia amazônica. Tal tendência, provavelmente lamentada por alguns antropólogos culturais brasileiros (Neves 1989), foi fundamental para o desenvolvimento da arqueologia na região. De particular interesse para esse trabalho é o conceito de "cultura de floresta tropical", definido por Steward (1948) e Robert Lowie (1948) no terceiro volume do Handbook.

\section{O CONCEITO DE CULTURA DE FLORESTA TROPICAL: 0 MODELO PADRÃO}

O conceito de cultura de floresta tropical foi uma categoria tipológica desenvolvida para descrever os padrões de organização econômica, social e política das populações indígenas da Amazônia e das florestas tropicais do leste da América do Sul. Além de tipológico, o conceito é também 
evolutivo, representando aproximadamente a categoria de "tribo" dos neo-evolucionistas norte-americanos (Feinman e Neitzel 1984).

O pensamento de Steward pode ser visto como uma mistura de elementos evolucionistas e difusionistas (Roosevelt 1980). Nesse sentido, o desenvolvimento das culturas de floresta tropical foi explicado como uma combinação de processos adaptativos locais com influências externas. Steward (1948: 885) inicialmente propôs ter sido a área do Circum-Caribe a principal matriz de influências culturais para as populações da floresta tropical. Posteriormente, considerou, devido à influência de Rouse (1953) e Meggers e Evans (1957), as terras baixas adjacentes aos Andes orientais como outra possível matriz (Steward e Faron 1959: 291). Em ambos os casos, esses modelos estabeleceram uma perspectiva que coloca a Amazônia em um contexto periférico na história pré-colonial da América do Sul (Lathrap 1973a; Roosevelt 1991a), uma perspectiva que de certa forma contrariava o conhecimento sobre a arqueologia da região obtido antes da $\mathrm{Se}$ gunda Guerra Mundial (Nordenskiöld 1929, 1930).

Uma conseqüência dessa perspectiva periférica foi a definição do conceito de cultura de floresta tropical muito mais pela ausência que pela presença de marcadores culturais - tais como arquitetura monumental e refinamentos na metalurgia (Lowie 1948: 1) - (Myers 1992). Outras características definidoras incluíam o cultivo de tubérculos, especialmente a mandioca; o desenvolvimento de uma tecnologia efetiva de navegação ribeirinha; o uso de redes para dormir; a descentralização política, acompanhada pela ausência de formas de religião organizadas ao redor de cultos em templos (Lowie 1948). Dentre essas características, fundamentais para Lowie (1948:2) eram a domesticação de tubérculos e o desenvolvimento das técnicas de navegação ribeirinha. Essas características explicariam a expansão da cultura de floresta tropical por lugares distantes na Amazônia e no leste da América do Sul. O foco na utilização dos caminhos fluviais lançou as bases para o estabelecimento do que se tornou um dispositivo explicativo fundamental na arqueologia amazônica: a distinção entre ambientes de várzea e terra firme.

Virtualmente toda a arqueologia realizada na Amazônia desde os anos 40 foi empreendida sob a influência do conceito de cultura de floresta tropical. No entanto, na antropologia cultural, há cada vez mais elementos para uma crítica das premissas que embasam esse "modelo periférico", também chamado de standard model (Viveiros de Castro 1996). No caso da arqueologia percebe-se também uma tendência crescente de avaliação crítica das premissas desse modelo. Tal crítica está direcionada aos diferentes usos de explanações com bases ecológicas apresentadas pelos arqueólogos que atuam na Amazônia nos últimos cinqüenta anos, principalmente as tentativas de explicar os padrões pré-coloniais locais de organização política. Porém, a melhor evidência para uma crítica da perspectiva periférica pode ser vista nos resultados de pesquisas recentes que modificam os quadros cronológicos prévios estabelecidos para a região.

\section{NOVAS PERSPECTIVAS CRONOLÓGICAS}

A referência cronológica padrão utilizada na Amazônia foi proposta por Meggers e Evans (1961) através da definição de quatro "horizontes" cerâmicos para a floresta tropical: "zonado hachurado", "borda incisa", "policromo" e "inciso e ponteado". Esses horizontes foram definidos com base na decoração e nos tipos de tempero achados nos 22 complexos cerâmicos então conhecidos na área de floresta tropical. Consistente com a perspectiva periférica, para os quatro horizontes foram designadas tanto uma origem externa à Amazônia como uma duração cronológica bastante curta (Meggers e Evans 1961: 381-2). Embora posteriormente modificado, prin- 
cipalmente em termos da duração de cada horizonte, agora denominado "tradição", esse esquema tem sido empregado constantemente durante os anos (Meggers e Evans 1983; Miller et al. 1992; Simões e Kalkmann 1987).

No esquema acima descrito, há uma preferência pelo estabelecimento de cronologias relativas através da seriação de atributos cerâmicos, principalmente o tempero, um método influente ainda empregado por alguns arqueólogos ainda ativos nas terras baixas (Meggers e Evans 1970; Miller et al. 1992). As justificativas para o emprego desse método estão baseadas em uma série de premissas duvidosas: que fragmentos decorados representariam uma amostra pequena em uma coleção; que a variabilidade de técnicas decorativas em determinadas indústrias seria muito grande e, finalmente, que superfícies pintadas seriam vulneráveis à erosão (Meggers 1995: 20).

Durante os anos, a adesão à perspectiva periférica e o uso de cronologias relativas contribuíram para o estabelecimento de cronologias pouco profundas para a Amazônia (Meggers e Evans 1983). Embora essa perspectiva tenha sido criticada a partir dos anos 60 (Lathrap 1968a, 1974, 1977), essa crítica, apesar de inovadora, foi apoiada por poucos dados empíricos. Nos últimos anos, porém, há cada vez mais elementos que apontam para uma ocupação pré-colonial bastante antiga da Bacia Amazônica, chegando pelo menos até a transição entre o Pleistoceno e o Holoceno (Roosevelt et al. 1996).

Atualmente, as datas mais antigas para o início da ocupação humana da Amazônia chegam a mais ou menos 10.500 anos AP, resultado das escavações na caverna da Pedra Pintada, localizada próximo à várzea do Rio Amazonas, em Monte Alegre, estado do Pará (Roosevelt et al. 1996). Pedra Pintada é no momento o sítio mais bem datado da Amazônia, com mais de 50 datas obtidas por diferentes métodos. Juntamente com Roosevelt, outros autores encontraram evidências, obtidas em áreas distantes da várzea amazônica, para o recuo da cronologia de ocupação para o início do
Holoceno. Esses trabalhos, porém, não foram ainda exaustivamente datados e publicados para que se possa avaliá-los em detalhe. Dentre esses sítios cabe destacar a Gruta do Gavião, situada na Serra dos Carajás, com datas que chegam até $8.140 \pm 130$ AP (Magalhães 1994) e os sítios a céu aberto da fase Itapipoca, na bacia do alto Madeira, em Rondônia (Figura 1), com sequiências que chegam a $8.320 \pm 100$ AP (Miller et al. 1992).

Em suas pesquisas no baixo Amazonas, Roosevelt (1995; Roosevelt et al. 1991) encontrou também os vestígios mais antigos para a produção cerâmica nas Américas, sem dúvida a evidência empírica mais importante para a crítica da perspectiva periférica. Na caverna da Pedra Pintada e no sambaqui fluvial da Taperinha (Figura 1), o último situado próximo à cidade de Santarém, Roosevelt escavou cerâmicas datadas em, respectivamente, $7.090 \pm 80$ BP e $7.580 \pm 215$ AP (Roosevelt 1995: 123). Essas datas contribuem para a rejeição de hipóteses que postulavam uma origem exógena da cerâmica na Amazônia, que teria sido introduzida na região a partir de centros originais localizados no oeste ou noroeste da Amazônia (Meggers 1979: 256; 1987: 161).

Antes de Roosevelt, Simões (1981) já havia obtido datas de cerca de 5.500 anos AP para a produção de cerâmica, pertencentes à fase Mina, nos sambaquis do litoral do Pará. Talvez por haver sido publicado em português, esse trabalho não recebeu muita atenção fora do Brasil. Por outro lado, Roosevelt (1995) mostrou como datas antigas para produção cerâmica obtidas pelo laboratório do Smithsonian Institution foram descartadas por Simões e Meggers por não se ajustarem à perspectiva conceitual desses pesquisadores.

Um exame das datas disponíveis para o início da produção cerâmica no norte da América do Sul (Hoopes 1994) revela que os dados obtidos por Roosevelt no baixo Amazonas não são aberrantes (Roosevelt 1995). A existência de complexos cerâmicos antigos ao longo da várzea amazônica já havia sido sugerida por Lathrap (1974), 
mas essa hipótese não pôde ser testada anteriormente devido à falta de dados empíricos na Amazônia brasileira. Novas pesquisas nessa área deverão trazer informações adicionais sobre esses complexos. Por exemplo, na bacia do alto Rio Negro, próximo à fronteira do Brasil com a Colômbia no noroeste da Amazônia, Neves (1998) identificou cerâmicas não-decoradas temperadas com cariapé e datadas em 3.200 anos AP em uma área adjacente a um antigo meandro abandonado do Rio Uaupés (Figura 1).

As hipóteses de Lathrap sobre a existência de um centro antigo, durante o Holoceno, de desenvolvimento cultural nas áreas de várzea da floresta tropical foram propostas em uma série de trabalhos com foco na arqueologia do norte da América do Sul (Lathrap 1973b, 1973c, 1974). Esses trabalhos apontam, dentre outros aspectos, para evidências sobre antigas redes de comércio (Lathrap 1973a; Myers 1981) e para a presença de elementos de floresta tropical na iconografia dos primeiros complexos cerimoniais andinos como Chavín de Huantar (Lathrap 1973b). Em uma discussão sobre as cerâmicas sul-americanas mais antigas conhecidas nos anos 70-como Valdivia, Bacia de Guayas, Equador; Puerto Hormiga, bacia do baixo Magdalena, próximo ao litoral caribenho da Colômbia; fase Alaka, litoral das Guianas - Lathrap (1974) propôs que complexos mais antigos deve-

\section{FIGURA 1}

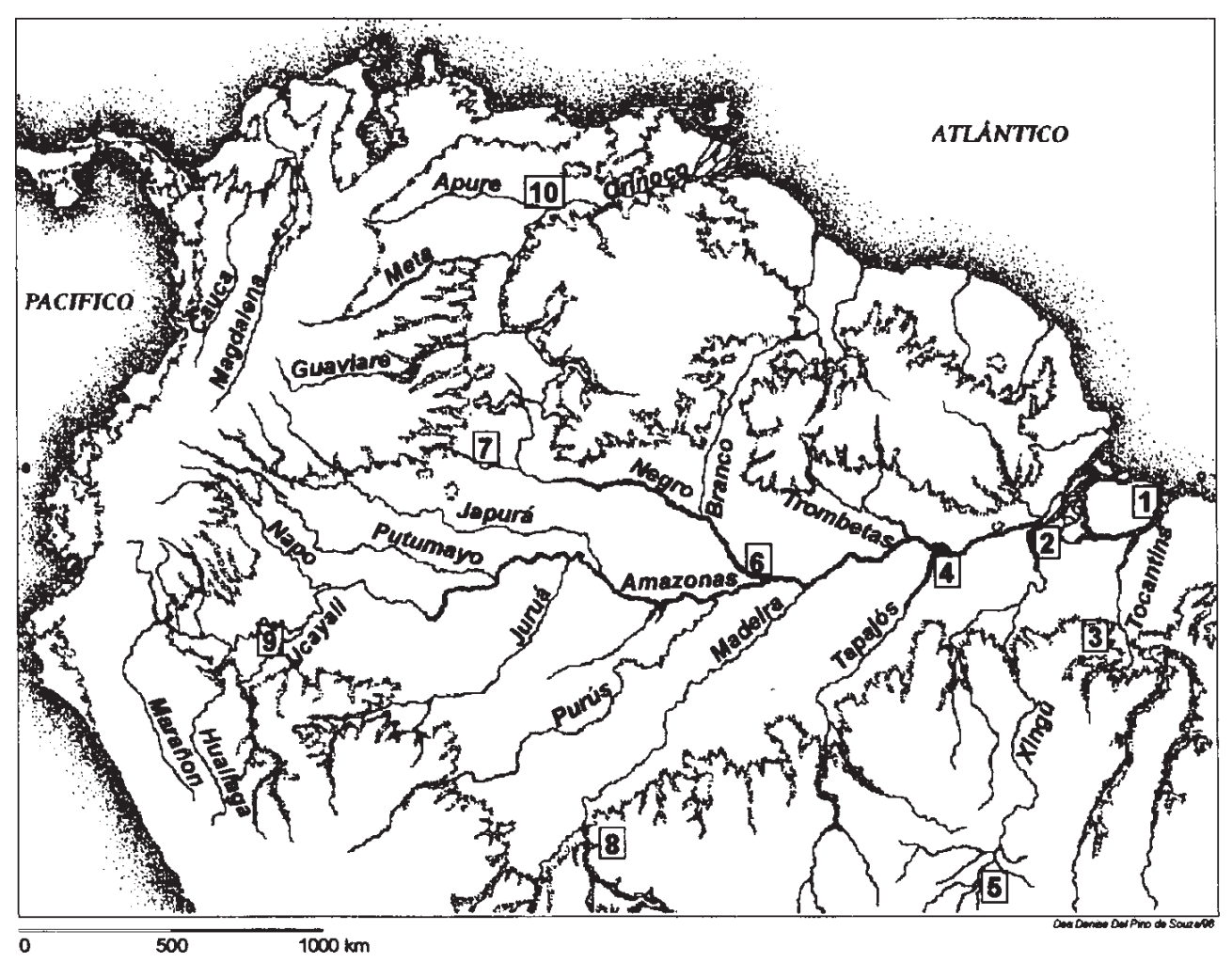

Locais e áreas mencionados no texto: 1. Ilha de Marajó; 2. Caxiuanã; 3. Serra dos Carajás; 4. Santarém/Taperinha/Pedra Pintada; 5. Bacia do alto Xingu ; 6. Área de confluência dos rios Negro e Solimões; 7. Alto Rio Negro; 8. Bacia do alto Madeira; 9. Rio Uacayali; 10. Confluência dos rios Apure e Orinoco (sítio Agüerito). 
riam ser encontrados ao longo das várzeas da Amazônia central ou do norte do continente. Seu raciocínio era cristalino: as cerâmicas então conhecidas eram diferentes o bastante umas das outras para que se aceitasse a hipótese de difusão de um complexo para o outro, uma afirmação confirmada por pesquisas adicionais sobre esse problema (Raymond 1995; Raymond et al. 1994). Esta era uma crítica direta à hipótese de Meggers, Evans e Estrada (1965) postulando uma migração antiga do Japão para o Equador como sendo responsável pela introdução da cerâmica na América do Sul. De acordo com Lathrap, as cerâmicas mais antigas da América do Sul deveriam ser procuradas em áreas de florestas tropicais como a Amazônia ou partes da Colômbia, e não em uma implausível migração marítima através do Pacífico.

Os trabalhos recentes de Roosevelt confirmam a hipótese de Lathrap, já que indicam que a cerâmica mais antiga das Américas provém do baixo Amazonas, próximo ao centro de origem por ele proposto (Roosevelt 1995; Roosevelt et al. 1991). É necessário, porém, que se avalie se essas cerâmicas se difundiram para outras áreas e geraram os outros complexos cerâmicos conhecidos, conforme propôs Lathrap. Recentes hipóteses sobre o aparecimento de cerâmica nas Américas tendem a indicar origens múltiplas e não uma difusão de um único centro (Barnett e Hoopes 1995). Além disso, trabalhos recentes na Bacia de Guayas, no Equador (Lamb e Vargas 1995), indicam que a economia das sociedades produtoras de cerâmicas nessa área não se ajusta ao padrão de floresta tropical proposto por Lathrap e seus colaboradores (Lathrap, Marcos e Zeidler 1977).

Malgrado os ainda pouco numerosos dados disponíveis, as perspectivas variáveis sobre a antigüidade da ocupação humana e as origens da produção cerâmica na América do Sul indicam que não é mais possível que se continue a focalizar a Amazônia como uma área periférica durante todo o processo de ocupação humana do continente.

\section{DETERMINISMO AMBIENTAL NA ARQUEOLOGIA AMAZÔNICA}

A primeira tentativa para avaliar na Amazônia a seqüência de desenvolvimento da cultura de floresta tropical esboçada no Handbook foi realizada por Meggers e Evans (1957) em suas importantes pesquisas na foz do Amazonas. Tais pesquisas marcaram o início de uma forte influência na arqueologia brasileira que ainda se faz presente (Meggers 1985, 1992a). A foz do Amazonas foi escolhida porque pesquisas anteriores nessa área tinham indicado a ocorrência, na porção oriental da Ilha de Marajó (Figura 1), de grandes aterros artificiais associados a cerâmicas decoradas com sofisticadas técnicas incluindo a policromia, modelado, incisão e excisão. Como essas características se assemelham mais a um padrão arqueológico do tipo circum-Caribe que a um padrão de floresta tropical, esta situação parecia ser uma anomalia dentro do quadro proposto por Steward para as terras baixas. A sucessão cultural proposta por Meggers e Evans para a Ilha de Marajó foi composta por cinco fases, definidas com base na análise cerâmica. Sua interpretação da fase Marajoara, associada aos aterros e à cerâmica polícroma, atendeu às expectativas apresentadas no Handbook: o registro arqueológico foi explicado como o correlato de um processo de "decadência" cultural, causado por fatores ambientais, de uma suposta população exógena que apresentava inicialmente um padrão de organização política do tipo cacicado que se transformou em um padrão do tipo floresta tropical menos complexo (Meggers e Evans 1957). Como consequiência do uso de cronologias relativas, Meggers e Evans acreditaram que o processo de decadência dos construtores de aterros da fase Marajoara tinha sido relativamente rápido, um indicador da força dos fatores limitantes ambientais atuantes na Amazônia.

As evidências da foz do Amazonas foram também influentes no desenvolvimen- 
to de uma hipótese geral que relacionava fatores ambientais, principalmente o potencial agrícola, a variáveis que fixariam limites à emergência da complexidade social (Meggers 1954: 821). A questão fundamental nesse caso está relacionada ao entendimento dos padrões de mobilidade dos assentamentos, um ponto que está no cerne desse e de outros usos subsequientes do raciocínio ecológico na antropologia amazônica (Gross 1975; Lathrap 1968a; Meggers 1971). Tal perspectiva interpreta os padrões de mobilidade contemporâneos das sociedades indígenas na Amazônia como uma resposta adaptativa à suposta escassez de recursos naturais, como, por exemplo, proteína animal (Lathrap 1968a; Gross 1975) ou fertilidade do solo (Meggers 1971).

Padrões contemporâneos de mobilidade entre os índios da Amazônia, porém, são melhor explicados através de outros fatores que não unicamente os ecológicos. Já na década de 50, o estudo detalhado de Carneiro (1957) sobre a agricultura entre os índios Kuikuru da bacia do alto Xingu indicou a possibilidade de cultivo de uma mesma área por até noventa anos. Desse modo, a alta mobilidade dos assentamentos deve ser entendida a partir de modelos que incorporem outras variáveis tais como relações de parentesco ou disputas políticas no nível local (Neves 1995a). Há que se considerar também que padrões contemporâneos de mobilidade dos assentamentos são uma resposta à pressão exercida pelo ritmo desordenado de ocupação contemporânea da Amazônia (Beckerman 1979; Roosevelt 1989).

Finalmente, trabalhos posteriores na Ilha de Marajó mostraram que a duração da fase Marajoara foi muito maior que o inicialmente sugerido por Meggers e Evans (1957). Roosevelt (1991b) obteve datas que situam o início dessa fase no século IV d.C. e seu fim ao redor do século XIII d.C. Não se sabe ainda com clareza, no entanto, quais eram as atividades produtivas relacionadas à fase Marajoara. Brochado (1980) apresentou um modelo hipotético pressupondo a agricultura intensiva de cereais e tubérculos em campos elevados naturais - anti- gos terraços pleistocênicos - no leste da Ilha de Marajó. Tais terraços seriam, assim, funcionalmente semelhantes aos campos de cultivo elevados artificiais encontrados em outras áreas da América do Sul, como, por exemplo, llanos Mojos na Bolívia (Denevan 1966; Erickson); o litoral da Guiana Francesa (Rostáin 1991) ou a área de Barinas na Venezuela (Spencer e Redmond 1992).

O modelo de Brochado não foi ainda testado, embora a pesquisa de Roosevelt (1991b) no Teso dos Bichos e outros aterros de Marajó tenha sido até o momento a iniciativa mais sistemática de recuperação de dados paleobotânicos na arqueologia brasileira. Roosevelt visava recuperar evidências de cultivo intensivo de milho durante a fase Marajoara, já que suas pesquisas anteriores no médio Orinoco (Roosevelt 1980) estabeleceram uma correlação positiva entre o crescimento dos assentamentos da fase Corozal e a introdução de milho, uma evidência posteriormente confirmada por análises de isótopos de carbono em ossos humanos (van der Merwe et al. 1981).

Como Brochado (1980), Roosevelt (1987, 1991b, 1992) tem como premissa que a fase Marajoara seria o correlato arqueológico de um cacicado. Os resultados preliminares das pesquisas no Teso dos Bichos (Roosevelt 1991b) não trazem, no entanto, evidências conclusivas sobre o cultivo intensivo, ou mesmo esporádico, do milho na Ilha de Marajó durante a fase Marajoara (Roosevelt 1992:76). Nesse caso é plausível supor que o cultivo de tubérculos, ao invés apenas do cultivo de cereais, tenha sido uma atividade produtiva fundamental para os cacicados da Amazônia précolonial. Assim, pode-se refutar a hipótese de Roosevelt (1992: 76) que propôs que o padrão de cultivo de mandioca atualmente característico dos índios amazônicos seria um "retorno" a um padrão antigo, característico do formativo, resultado do contato europeu. Heckenberger (1996: 91), por exemplo, mostrou, através de analogias etnográficas, que no alto Xingu (Figura 1) populações que cultivavam mandioca ocuparam, no final do primeiro milênio d.C., 
grandes aldeias, com quase 1 km de diâmetro, cercadas por valas defensivas. Além disso, pelo menos no leste da Amazônia, o milho tende a ser cultivado por sociedades com alto padrão de mobilidade, normalmente sob pressão, devido à invasão de suas terras (Balée 1994; Viveiros de Castro 1992) porque essa planta necessita de um período de cultivo menor que a mandioca.

Se o raciocínio determinista foi introduzido na Amazônia por um trabalho que correlacionava potencial agrícola a padrões de organização social e política (Meggers 1954), foi justamente um trabalho em pedologia (Smith 1980) que ofereceu uma das críticas mais poderosas contra o determinismo ambiental: a chamada "ecologia histórica” (Balée 1994, 1995). Smith (1980) discutiu os processos de formação das chamadas terras pretas de índio, solos com sedimentos bastante escuros e com alta fertilidade encontrados em muitas áreas da Amazônia, normalmente associados a sítios arqueológicos. Previamente caracterizadas como formações naturais (Falesi 1974), as terras pretas têm as mesmas características físicas dos latossolos amazônicos mas propriedades químicas bastante diferentes: pHs mais básicos; maiores quantidades de húmus, nitrogênio, fósforo e cátions trocáveis (Pabst 1991).

Depois de Smith (1980), pesquisas arqueológicas e pedológicas têm trazido evidência para uma origem antrópica para as terras pretas. Esse parece ser o caso das terras pretas de Araracuara, no Rio Caquetá, na Amazônia colombiana (Eden et al. 1984) e na área de Caxiuanã (Figura 1), no baixo Amazonas (Kern 1996). Em Açutuba e outros locais no baixo Rio Negro, perto de Manaus, encontrou-se também uma correlação positiva entre terras pretas e sítios arqueológicos bastante grandes e densos, com sequiências de ocupação que vão desde o princípio do primeiro milênio a.C. até o século XVI d.C. (Heckenberger et al. 1998).

Embora a correlação positiva entre sítios arqueológicos e terras pretas tenha sido estabelecida, ainda são debatidos os mecanismos responsáveis pela formação desses sedimentos. Smith (1980:556) sugeriu que a acumulação de resíduos orgânicos, principalmente os carvões de fogueiras domésticas, resultantes de ocupações pré-coloniais de longa duração, seria o principal elemento causador. Em Araracuara propôs-se que a variação da cor do sedimento nos sítios arqueológicos com terras pretas está associada a padrões diferentes de uso do solo (Herrera et al. 1992: 102). É provável, porém, que terras pretas não sejam só o resultado de ocupações contínuas de longa duração. Mais uma vez em Araracuara, há evidências de que sedimentos aluviais foram também acrescentados à matriz de solo no processo de formação das terras pretas (Herrera et al. 1992: 102)

Pesquisas sobre o ritmo de formação das terras pretas estão ainda em andamento. Smith (1980: 564) sugeriu inicialmente que cerca de dez anos de ocupação contínua seriam necessários para a formação de um centímetro de terras pretas. Em Açutuba, há evidências preliminares que associam o escurecimento dos sedimentos ao advento da cerâmica polícroma da fase Guarita datado no local entre 970 e 1440 d.C. (Heckenberger et al. 1998). Tais dados preliminares indicam que, na Amazônia central, sítios arqueológicos com terras pretas resultaram de fato de décadas, se não séculos, de ocupação contínua, evidência adicional de que o padrão de mobilidade dos assentamentos amazônicos pré-coloniais era menos intenso que o atualmente verificado.

As evidências crescentes para uma origem antrópica das terras pretas têm uma implicação importante para a arqueologia amazônica: mostra que a paisagem amazônica, como nós a conhecemos hoje, não é só um produto da natureza, mas também da cultura, resultante de milênios de manejo humano, uma observação já feita por outros autores para o resto do continente americano (Adams 1994; Denevan 1992a; Stahl 1996).

Do mesmo modo que a pedologia e a arqueologia, pesquisas em etnobotânica indicam que o manejo ambiental, consciente ou inconsciente, entre os índios amazônicos contemporâneos, aumenta, ao invés de reduzir, a diversidade ecológica, 
como é o caso dos Ka'apor do Maranhão (Balée 1994: 136). Balée e Moore (1994) mostraram como o manejo de plantas é uma atividade muito antiga entre os Ka'apor e outros grupos falantes de línguas da família Tupi-Guarani através da comparação de nomes de plantas em cinco línguas TupiGuarani faladas por grupos atualmente habitantes de áreas ecológicas diferentes. Entre esses idiomas, os nomes para plantas intensivamente manejadas (domesticadas e semidomesticadas) têm taxas mais altas de semelhança que os nomes para plantas não domesticadas (Balée e Moore 1994: 371), uma indicação de que os nomes para plantas intensivamente manejadas nesses idiomas são palavras cognatas derivadas de um idioma falado há cerca de dois mil anos (Balée 1994: 138).

No caso dos Ka' apor, o manejo de plantas está relacionado ao cultivo de mandioca em roças "de toco" ou "de coivara". Nesse sentido, mudanças paisagísticas são conseqüências imprevistas das atividades produtivas corriqueiras (Balée 1994: 139). Há, porém, exemplos de transformação deliberada da paisagem por índios amazônicos. Entre os Kayapó, Posey (1986) verificou a formação deliberada de ilhas de plantas contendo recursos naturais. Os Kayapó não são, no entanto, habitantes tradicionais da floresta tropical, já que se instalaram nessas áreas há mais ou menos duzentos anos (Verswijer 1992). Assim, é interessante notar que suas práticas de manejo podem ter se desenvolvido originalmente nas áreas de cerrado do Brasil central que ocupavam anteriormente. Se for esse o caso, há elementos para se apoiar a hipótese de que as paisagens de cerrado do Brasil também foram transformadas intensivamente devido ao manejo humano (Flowers 1994).

Entre os Nukak, um grupo forrageiro da Amazônia colombiana, Politis (1996, 1997) encontrou evidências de que o manejo de plantas como palmeiras aumenta a diversidade ecológica dos ambientes por eles ocupados. O dados sobre os Nukak também são importantes porque indicam a possibilidade de sustento de uma sociedade forrageira na floresta tropical sem a prática da agricultura, ao contrário do que foi proposto por Headland e Bailey (1991). As datas pré-cerâmicas antigas obtidas por Roosevelt em Pedra Pintada (Roosevelt et al. 1996) apontam para a mesma direção, já que as reconstituições paleoecológicas disponíveis mostram que o baixo Amazonas era coberto por uma floresta tropical densa no final do Pleistoceno (Adams e Faure 1997). Em Pedra Pintada, dados sobre as atividades produtivas mostram uma economia diversificada baseada na coleta de diferentes espécies vegetais, assim como na pesca e na coleta.

Os resultados dessas pesquisas indicam que, na Amazônia, a natureza não oferece necessariamente um limite contra o crescimento demográfico ou a emergência da complexidade social, já que a natureza é parcialmente um produto da ação humana e não uma variável externa totalmente independente. Tal constatação é sugestiva o suficiente para lançar dúvidas ao determinismo ambiental extremo que caracteriza as pesquisas arqueológicas realizadas na Amazônia sob a influência de Meggers.

Essas evidências também fortalecem as críticas ao determinismo ecológico propostas por Lathrap (1968a, 1973, 1974, 1977) nas quais as várzeas amazônicas teriam sido centros importantes para a domesticação inicial de plantas e o início da produção cerâmica (Lathrap 1970a:104; 1977: 716). Nessa perspectiva, afloresta tropical, ou pelo menos partes dela, forneceu estímulo para o estabelecimento de formações sociais populosas, estáveis e sedentárias (Lathrap 1968a, 1968b, 1970a, 1973, 1974, 1977).

A hipótese de Lathrap derivou de uma discussão dos diferentes potenciais de subsistência das áreas de várzea e terra firme na Amazônia (Lathrap 1968a, 1968b), uma perspectiva posteriormente adotada por outros arqueólogos que trabalharam naárea (Meggers 1971; Roosevelt 1991). Seguindo Lowie (1948) e Steward (1948), Lathrap destacou a importância das adaptações fluviais na floresta tropical, principalmente em termos da grande e contínua disponibilidade de proteína animal - peixes, mamí- 
feros, répteis e aves (Lathrap 1968a, 1968b, 1970a). Tal concentração estável de recursos teria favorecido o crescimento demográfico de populações sedentárias, levando eventualmente à competição por recursos com dois possíveis resultados: a colonização de outras áreas de várzea ou a ocupação das áreas de terra firme mais pobres em recursos. Devido ao foco na Amazônia central como o centro de origem para a colonização de outras áreas da floresta tropical e áreas adjacentes, o modelo difusionista de Lathrap foi chamado "cardíaco“ (Carneiro 1971).

As premissas desse modelo foram aplicadas por Lathrap (1977) em sua proposta de que todos os sistemas agrícolas do Novo Mundo teriam derivado de um sistema antigo de cultivo de mandioca centrado nas várzeas da Amazônia e norte da América do Sul. Tal sistema por sua vez teria derivado de uma migração transatlântica pleistocênica de populações africanas para a América do Sul, que teriam sido responsáveis pela introdução da cabaça (Lagenaria siceraria) no continente. Nesse modelo, o crescimento populacional nessas comunidades sedentárias, encorajado pelo acesso contínuo à proteína animal, conduziria eventualmente à colonização de áreas ribeirinhas em toda a América neotropical (Lathrap 1977:738). Junto com essa expansão, sistemas de cultivo de "quintal" se tornariam mais complexos e eventualmente incorporariam várias espécies vegetais de importância econômica - matérias-primas, venenos, alimentos, medicamentos e alucinógenos. Seguindo Carl Sauer, Lathrap (1977: 739) sugeriu que o cultivo de mandioca teria sido incorporado cedo a esse sistema, resultando em sua domesticação há 5.000 anos. Para Lathrap (1977: 740) o início do cultivo de mandioca teria marcado o início de uma "revolução neolítica" nas Américas.

Embora o modelo neolítico de Lathrap tenha apresentado alguns cenários implausíveis, trabalhos recentes embasam algumas de suas premissas. Assim, há evidências crescentes para uma ocupação pleistocênica da América do Sul (Dillehay et al.
1992; Prous 1992, 1995), inclusive a Bacia Amazônica (Roosevelt et al. 1996). Do mesmo modo, os já mencionados estudos de manejo indicam um padrão de cultivo do tipo "quintal" entre diferentes grupos amazônicos como, por exemplo, os Kayapó (Flowers 1994; Posey 1986) e os Ka'apor (Balée 1994). Finalmente, dados do Vale do Casma, litoral central do Peru (Ugent et al. 1986) - longe, portanto, de qualquer centro plausível de domesticação de mandioca -, mostram que a mandioca já era consumida nessa região há quase 4.000 anos.

O modelo de Lathrap é baseado na premissa de uma diferença drástica entre ambientes de várzea e terra firme que ainda não foi testada. O modelo recente de Denevan (1996) oferece uma alternativa a essa dicotomia quando contempla padrões de uso combinado de recursos fluviais e de ambientes terrestres na Amazônia. Dados preliminares obtidos na área de confluência dos rios Negro e Solimões (Neves e Bartone 1988) tendem a apoiar esse mode1o, mas pesquisas adicionais em áreas distantes das várzeas amazônicas são necessárias para seu teste.

A partir dos anos 70, outra forma de argumento determinista foi introduzida na arqueologia amazônica. Nesse caso, uma série de modelos foram apresentados com o objetivo de correlacionar padrões no registro arqueológico com variáveis paleoambientais (Meggers 1977, 1979, 1982, 1987, 1990, 1991, 1992b, 1993-95, 1995; Meggers e Danon 1988; Meggers et al. 1988; Miller et al. 1992; Simões 1977). O Pronapaba - Programa Nacional de Pesquisas Arqueológicas na Bacia Amazônica (Simões 1977) foi desenvolvido justamente com esse objetivo, mas a ausência de publicação detalhada dos dados obtidos impede que seus resultados possam seravaliados no momento.

O uso inicial de dados paleoambientais feito por Meggers (1977, 1979) baseou-se na chamada "teoria dos refúgios" (Withmore e Prance 1987), desenvolvida para explicar a distribuição de espécies na Amazônia como consequiências de episódios de aridez no Pleistoceno e Holoceno. 
Desde então, porém, as premissas dessa teoria foram criticadas (Colinvaux 1987; Whitten 1979). De fato Meggers tem, em suas publicações mais recentes, se distanciado de explicações baseadas nas premissas da teoria de refúgio (Meggers 1992b, 1993-95, 1995; Meggers e Danon 1988), sem abandonar o foco em mudanças ambientais como fatores limitantes na Amazônia.

Assim, hiatos na sequiência arqueológica da Ilha de Marajó foram correlacionados por Meggers e Danon (1988) a intervalos áridos, deduzidos da palinologia, ao redor de 2.800 a 2.000 anos AP. Tal interpretação foi estendida para explicar hiatos no mesmo período em seqüências arqueológicas de diferentes áreas tais como Llanos de Mojos (terras baixas da Bolívia); Lago Silves/baixo Uatumã (Amazônia central) e o baixo Xingu (Meggers 1995: 31). Esses hiatos foram interpretadas por Meggers como respostas a intervalos áridos gerados por episódios do tipo El Niño-Southern Oscillation (Enso), que teriam ocorrido no litoral Pacífico da América do Sul. Perota e Botelho (1992) utilizaram o mesmo raciocínio para interpretar o registro dos sambaquis fluviais parcialmente submersos do baixo Xingu. Uma vez que essas interpretações são baseadas em materiais inéditos ou parcialmente publicados pelo Pronapaba, é necessário que se espere pela publicação dos dados completos do projeto para que se possa avaliá-las. Uma possibilidade alternativa seria a investigação de respostas semelhantes no registro arqueológico de áreas na América do Sul que supostamente também sofreram episódios secos como consequiência de fenômenos de Enso antigos (Meggers 1995: 32).

A compreensão da interação dinâmica entre variáveis ambientais e dinâmicas sociais na Amazônia pré-colonial é ainda um problema não resolvido. Parece claro, no entanto, que modelos deterministas simples são insuficientes para explorar esse problema. Descola $(1986,1994)$ e ReichelDolmatoff $(1971,1976)$ já mostraram em suas etnografias que, entre alguns grupos indígenas da Amazônia, prevalece uma ideologia "homeostática" que fornece mecanismos de controle que regula os padrões de uso de recursos naturais. Tal ideologia poderá ser instrumental na explicação dos intervalos aparentemente longos de estabilidade que se verificam no registro arqueológico da Amazônia sem que se utilize o determinismo ambiental ortodoxo como recurso.

\section{MODELOS LINGÜISTICOS EM ARQUEOLOGIA AMAZÔNICA: A IDENTIFICAÇÃO DE FRONTEIRAS ÉTIICAS PELA ARQUEOLOGIA}

Donald Lathrap e alguns de seus estudantes (Brochado 1984; Lathrap 1970a; Lathrape Oliver 1987; Noelli 1996; Oliver 1989) são os proponentes mais importantes de modelos baseados em dados lingưísticos na Amazônia. Baseado nas premissas do "modelo cardíaco", Lathrap apresentou uma hipótese geral para a distribuição de línguas indígenas (1970a: 6883 ) propondo que os dois troncos lingüísticos mais difundidos das terras baixas, Arawak e Tupi, tiveram uma origem comum na Amazônia central ao redor de 5.000 anos AP. Tal hipótese foi baseada na correlação dos supostos locais de origem dessas protolínguas com a distribuição de complexos cerâmicos nas terras baixas, em oposição aos modelos lingüísticos predominantes na década de 60, que reconheciam uma origem na Amazônia ocidental para esses troncos lingüísticos (Noble 1965). O modelo de Lathrap foi criticado por lingüistas (Migliazza 1982; Urban 1992, 1996) e arqueólogos que trabalharam nas terras baixas. Evans (1971), por exemplo, apontou para os problemas conceituais envolvidos na correlação entre língua e cultura material, uma objeção posteriormente repetida por outros arqueólogos atuantes na Amazônia (Meggers e Evans 1973; Roosevelt 1992). É verdade, no entanto, que alguns dos proponentes dessas críticas 
acabaram por modificá-las, já que suas publicações posteriores postulam uma certa correspondência entre língua e cultura material (Meggers e Evans 1981).

O modelo arqueológico-lingüístico de Lathrap gerou dois trabalhos de amplo espectro que tentaram aplicar suas premissas em um contexto mais amplo (Brochado 1984; Oliver 1989). Brochado (1984) organizou dados dispersos para fundamentar a hipótese de uma origem na Amazônia central, há mais ou menos 2.500 anos AP, para as línguas proto-Guarani e proto-Tupinambá da família lingüística Tupi-Guarani. O correlato arqueológico dos falantes dessas protolínguas seriam as cerâmicas da subtradição Guarita da Tradição Polícroma da Amazônia (Brochado 1984: 321).

O modelo de Oliver (1989) pode ser visto como um espelho do modelo de Brochado. Apesar das sugestões iniciais de Brochado (1984), Brochado e Lathrap (1982), Lathrap (1970a) e Rouse (1985, 1986), todas elas baseadas em revisões da literatura, não houve, até o final da década de 80 , tentativas de correlação entre supostas ocupações proto-Arawak e complexos cerâmicos na Amazônia, particularmente no baixo Rio Negro. Oliver realizou essa tarefa com o desenvolvimento de um modelo geral para a expansão das línguas Arawak e da cerâmica polícroma da Amazônia central para o norte da América do Sul.

Oliver sugeriu que, por volta de 6.000 anos AP, populações falantes de línguas proto-Arawak ocupavam a Amazônia central. Dessas populações ancestrais um grupo teria se expandido em direção à bacia do alto Rio Negro Superior, envolvendo a expansão do que Oliver (1989: 487) denominou “Tradição Polícroma Antiga da Amazônia". Um correlato arqueológico dessa expansão poderia, por exemplo, ser encontrado nas cerâmicas polícromas de 5.700 anos AP encontradas no sítio de Agüerito (Figura 1), situado na confluência dos rios Apure e Orinoco, na Venezuela central (Zucchi, Tarble e Vaz 1984). Lathrap e Oliver (1987) sugeriram serem essas as cerâmicas polícromas mais antigas conhecidas nas Américas (Oliver 1989: 487).
O raciocínio de Oliver é um desenvolvimento da hipótese de Brochado e Lathrap (1982) propondo o surgimento de cerâmicas com decoração polícroma na Amazônia central há cerca de 6.000 anos AP (Lathrap e Oliver 1987). O registro arqueológico do Rio Negro não tem, no entanto, sustentado essas hipóteses até o momento: trabalhos preliminares não têm mostrado evidências de cerâmicas polícromas com datas tão antigas no alto e baixo Rio Negro (Heckenberger et al. 1998; Neves 1997; Zucchi 1991, 1993). No alto Rio Negro, a decoração polícroma está ausente nos complexos cerâmicos mais antigos da região, datados em cerca de 3.200 e 2.500 anos AP (Neves 1997, 1998). No baixo Rio Negro, as seqüências arqueológicas indicam que a cerâmica Guarita, o complexo polícromo mais antigo da área, só surge ao redor do final do primeiro milênio d.C., muito posteriormente ao sugerido por Lathrap, Oliver e Brochado (Heckenberger et al. 1998).

Finalmente, há os problemas adicionais trazidos pela identificação das cerâmicas antigas do baixo Amazonas (Taperinha e Pedra Pintada): estas cerâmicas são temperadas principalmente com areia (Roosevelt 1995), ao contrário do sugerido por Brochado e Lathrap, que os complexos antigos deveriam ser temperados com cauixi.

Os dados preliminares acima expostos colocam dois problemas gerais aos modelos de Lathrap, Brochado e Oliver. Primeiramente, sugerem que se deve procurar outro correlato arqueológico para as supostas migrações Arawak desde o Rio Negro até o Caribe. Em segundo lugar, questionam as hipóteses gerais de Lathrap (1970a), Brochado (1984), Rouse (1985) e Oliver (1989), que sugerem uma origem na Amazônia central para os troncos lingüísticos Arawak e Tupi.

Tentativas de correlação entre o registro arqueológico e dados lingüísticos foram também realizadas por Meggers nos anos 70 e no início dos anos 80, em várias contribuições inovadoras que visavam explicar a distribuição de línguas indígenas na Amazônia com base na já mencionada teoria dos refúgios florestados (Meggers 
1977, 1979, 1982) ou em supostos episódios de mudanças climáticas no passado (Meggers 1987). Trabalhos lingüísticos (Migliazza 1982) trouxeram apoio às hipóteses apresentadas nesses trabalhos, mas a própria relutância de Meggers e Evans (Evans 1971) em aceitar correlações entre língua e cultura material torna difícil o teste dessas hipóteses.

O problema da correlação entre padrões arqueológicos e linguiísticos nas terras baixas da América do Sul é uma tarefa necessária mas problemática. Necessária porque a identificação lingüística é tradicionalmente utilizada como um índice para identificação étnica na antropologia da região. Partindo-se da premissa que a pesquisa em arqueologia pré-colonial no Brasil tem a tarefa de realizar história indígena (Neves 1995b), é quase impossível escapar do emprego de critérios de identificação baseados na lingüística. Por outro lado, se o estabelecimento dessas correlações é menos problemático em contextos insulares, como no Caribe e na Polinésia (Kirch e Green 1987; Rouse 1986, 1992), em outras partes do mundo, esse permanece um dos problemas metodológicos básicos da arqueologia (Blench e Spriggs 1997) à medida que a disciplina se distancia cada vez mais dos dogmas do processualismo.

Os registros etnográficos e etno-históricos das terras baixas são ambíguos sobre essa questão. Há dados indicando a existência de sistemas multiétnicos regionais em diferentes áreas da Amazônia e do norte da América do Sul. Os dados etnográficos provêm de áreas localizadas principalmente nas periferias das fronteiras de colonização no Brasil e seus países vizinhos, como a bacia do alto Rio Negro (Jackson 1983); a bacia do alto Xingu (Galvão 1979; Heckenberger 1996); o planalto das Guianas (Butt-Colson 1973; Riviére 1984; Thomas 1972); a bacia do Ucayali (Erikson 1992; Kästner 1992); a bacia do Orinoco (Arvelo-Jiménez e Biord 1994). A historiografia indica casos em que esses sistemas foram totalmente desmantelados durante o período colonial em áreas onde atualmente poucas, ou nenhuma, sociedades indígenas sobreviveram: as Antilhas menores e o litoral caribenho da América do Sul (Dreyfuss 1993; Farage 1991; Whitehead 1988, 1990, 1993); o Rio Solimões (Porro 1993, 1994, 1996; Sweet 1974); os llanos da Colômbia e Venezuela (Arvelo-Jiménez e Biord 1994; Biord 1985; Morey e Morey 1975), dentre outras regiões.

Sistemas regionais têm algumas características comuns: são multiétnicos e multilingüísticos; seus limites são fluidos; a integração intra-sistema é construída ao longo de diferentes vínculos, como comércio, casamento e guerra. Tais sistemas variam com o passar do tempo em termos da composição étnica e padrões de integração interna, dentro da base estrutural provida por padrões de casamento, comércio e guerra.

A visibilidade arqueológica de sistemas regionais na Amazônia ainda não foi avaliada, embora alguns estudos preliminares tenham sido feitos para avaliar sua antigüidade e desenvolvimento (Heckenberger 1996; Neves 1998). Ainda é difícil no momento apresentar uma fórmula geral de identificação arqueológica de tais sistemas, se realmente tal fórmula existe, já que a aceitação acrítica de correlações positivas entre, por exemplo, complexos cerâmicos e línguas indígenas apresenta muitos problemas metodológicos. É certo que a visibilidade arqueológica potencial desses sistemas deve variar, já que depende em parte do tipo de bens trocados, bem como da intensidade e da variabilidade desses padrões de troca. Na bacia do alto Xingu, por exemplo, grupos locais, que falam diferentes idiomas, são regionalmente integrados através de redes de troca que incluem também vasilhames cerâmicos (Basso 1973). Nesse caso as cerâmicas são produzidas apenas pelas mulheres Waurá-falantes de uma língua Arawak - mas as cerâmicas Waurá são as únicas consumidas no alto Xingu. As aldeias da região têm o mesmo plano geral circular, com malocas, localizado em suas periferias. Desse modo, sem o recurso dos dados etnográficos, arqueólogos poderiam interpretar o registro do alto Xingu do modo como essas sociedades são organizadas hoje-como o produto de uma única 
“cultura". A distribuição de um único estilo cerâmico nessa área provê, por outro lado, um indicador material para o sistema regional, mesmo se, com base nos restos cerâmicos, não seja possível identificar os diferentes grupos étnicos atualmente incorporados a esse sistema. Heckenberger (1996) demonstrou a antigüidade pré-colonial do sistema do alto Xingu, provendo também uma reconstrução de seu desenvolvimento histórico, inclusive o processo de agregação de grupos étnicos diferentes.

O alto Rio Negro é outro caso famoso de sistema multilinguiístico na Amazônia (Jackson 1983). Neves (1998) demonstrou a antigüidade pré-colonial desse sistema utilizando dados arqueológicos e a tradição oral indígena. Diferente do caso do alto Xingu, há no alto Rio Negro uma diferença básica entre os padrões decorativos da cerâmica produzidos pelo grupos Baniwa (Arawak), com decoração pintada em vermelho e vermelho sobre branco, e as cerâmicas produzidas pelos diferentes grupos Tukano, com decoração resistente em negro. Considerando-se, porém, que há mais de dez diferentes línguas Tukano faladas na área, as cerâmicas não funcionam como indicadores precisos de limites étnicos neste caso.

Os casos relatados indicam que tentativas de correlação entre língua e cerâmica na Amazônia deverão ser realizadas através de pesquisas regionais, com a chamada "abordagem histórica direta", em áreas onde há continuidade histórica entre populações indígenas contemporâneas e seus antepassados. No momento atual, é difícil aceitar modelos gerais baseados em tais correlações, apesar das sugestivas conexões espaciais, temporais e cronológicas por eles propostas.

\section{A AVALACC̈ÃO DO IMPACTO DO CONTATO EUROPEU NA AMAZÔNIA}

O problema da avaliação do impacto da conquista européia sobre padrões pré-coloniais de organização social e política na
Amazônia foi recolocado na agenda de debates da região por Roosevelt (1989). Embora Lathrap e seus discípulos, notavelmente Myers (1973, 1981), já tivessem chamado a atenção para as transformações resultantes da conquista, esses autores estavam melhor familiarizados com dados do alto Amazonas, que representa uma porção relativamente pequena da bacia. Roosevelt, por sua vez, teve acesso a áreas no baixo Amazonas que permaneceram virtualmente fechadas para os pesquisadores não alinhados aos paradigmas teóricos de Meggers e Evans (Roosevelt 1992b, 1996).

A hipótese principal de Roosevelt é baseada em um fato bem conhecido dos familiarizados à antropologia amazônica: um breve exame da distribuição das sociedades indígenas contemporâneas na região mostra que a maioria das áreas de várzea do baixo e médio Amazonas não são mais ocupadas por populações indígenas numerosas. A única exceção no Brasil são os Tikuna do alto Solimões, cuja ocupação inicial nessa área remonta provavelmente ao século XVIII (Nimuendajú 1982; Porro 1996). Desse modo há que se ter cautela na utilização de padrões indígenas atuais de organização social, política e econômica na Amazônia na explicação da diversidade de padrões que prevaleciam antes do século XVI (Roosevelt 1989).

A crítica de Roosevelt (1989) foi dirigida ao modo como Meggers (1971) empregou analogias etnográficas para exemplificar o suposto poder de fatores limitantes ambientais atuando na Amazônia. As utilizações feitas por Meggers desse tipo de analogia modificaram-se ao longo dos anos (Meggers e Evans 1979). Em sua forma atual, estão baseadas na premissa metodológica de que uma fase arqueológica seria o correlato de uma comunidade local pré-histórica (Meggers 1990; Meggers e Evans 1980). Esta é uma diferença marcante dos trabalhos iniciais de Meggers e Evans (1957) que mostravam uma recusa explícita em correlacionar fases com quaisquer formas de organização social (Meggers 1990, 1991, 1992b, 1993-95, 1995).

Os procedimentos de campo emprega- 
dos no estabelecimento dessas analogias estão baseados na escavação, em níveis artificiais, de poços teste. As cerâmicas obtidas são classificadas em seriações visando a definição das fases. As fases cerâmicas definidas para os níveis dos poços teste são então comparadas à cerâmica dos mesmos níveis obtida em outros poços teste no mesmo sítio. Se esses níveis contiverem cerâmicas pertencentes a fases diferentes, assumese então que elas representam ocupações diferentes. É desse modo que Meggers explica a formação dos grandes sítios arqueológicos encontrados ao longo das várzeas amazônicas (Heckenberger et al. 1998; Hilbert 1968; Myers 1973; Neves e Bartone 1998). Seguindo esse raciocínio, o tamanho desses sítios de grande porte não seria correlato ao tamanho dos assentamentos précoloniais, já que representam reocupações sucessivas dos mesmos locais por populações que residiam em aldeias pequenas (Meggers 1995: 27).

O argumento de Meggers é problemático porque ignora a possibilidade de variabilidade interna da cerâmica durante uma mesma ocupação, ao mesmo tempo em que ignora o fato de que vários fatores naturais e antrópicos estão ativamente envolvidos nos processos de formação de sítios arqueológicos na floresta tropical (DeBoer e Lathrap 1979; DeBoer et al. 1996). Além disso, mesmo que se aceitem as premissas deste argumento, a avaliação independente dos dados não pode ser feita, já que nenhum perfil de escavação ou descrição da composição de vestígios por nível foi ainda apresentada pelo Pronapaba. As evidências são freqüentemente apresentadas de forma incompleta, de modo que apenas “casos exemplares" são mostrados, permanecendo inédita a grande quantidade de dados gerados, mas nunca publicados, por esse programa nos últimos vinte anos (Meggers et al. 1988; Miller et al. 1992).

A nova utilização feita por Meggers do conceito de fase permitiu a apresentação de modelos de movimentação de aldeias nos casos em que dados regionais são disponíveis. Novamente, o objetivo é mostrar que os assentamentos pré-coloni- ais amazônicos eram pequenos, pouco densos e de curta duração. O procedimento, nesse caso, é também baseado no uso de seriações, mas como se apresentam poucas datas absolutas não há certeza sobre a duração do processo de movimentação de aldeias ou mesmo sobre a duração de cada ocupação individual (Meggers 1995: 28). Finalmente, esses supostos processos são comparados a processos contemporâneos de movimentação de assentamentos através de dados obtidos com grupos indígenas contemporâneos como os Kayapó, Akawaio ou o Jivaro (Meggers 1993-95, 1995). Assim, dados sobre os Akawaio, um grupo assentado no planalto das Guianas, são empregados para explicar o registro arqueológico do baixo Tocantins, uma área onde a disponibilidade potencial de proteína animal, representada pela fauna aquática, é muito maior que no planalto das Guianas. Dados sobre a movimentação de aldeias dos Kayapó, apresentados por Verswijver (1978), são também constantemente empregados. Publicações posteriores desse autor, no entanto, mostram que os Kayapó não podem ser reconhecidos como uma população amazônica tradicional (Verswijver 1992: 337). Eles são, na realidade, uma população com uma longa história de adaptação a áreas de cerrado que penetrou no sudeste amazônico nos últimos dois séculos (Flowers 1994). Grupos indígenas do cerrado, como foram os Kayapó, são conhecidos pelo seu alto padrão de mobilidade sazonal, incluindo expedições de longa duração. Além disso, a forte pressão da expansão da sociedade nacional sobre as terras indígenas como as dos Kayapó é parcialmente responsável pelos processos de divisão e mobilidade de assentamentos verificados entre eles. Como sempre, Meggers explica esses exemplos de mobilidade com um argumento ecológico, como a baixa capacidade de suporte do meio ambiente. Tais analogias não são, no entanto, pertinentes porque são comparadas áreas com características ecológicas bastante diferentes (Meggers 1995: 33). 
As observações acima apresentadas indicam que é correta a crítica de Roosevelt (1989), mas não há no momento elementos arqueológicos pouco ambíguos para testar a hipótese de Meggers sobre a formação dos grandes sítios arqueológicos da várzea amazônica. Os poucos relatos feitos pelos cronistas europeus que descreveram a Amazônia nos séculos XVI e XVII (Porro 1996) foram usados por Roosevelt (1987, 1989, 1991a) e outros (Denevan 1992a; Guapindaia 1993; Porro 1996; Sweet 1974) para indicar a existência de grandes e densos assentamentos nessas áreas. Essas informações devem, no entanto, ser checadas por dados arqueológicos sobre o tamanho, a densidade e a duração dos sítios para que essas narrativas possam ser avaliadas de maneira independente. No baixo Rio Negro, próximo às várzeas da Amazônia central, dados preliminares apontam para ocupações bastante densas, estáveis e de longa duração no sítio de Açutuba (Figura 1), que apresenta profundos depósitos de terra preta antropogênica; alta densidade de restos cerâmicos (por exemplo, mais de 8.000 fragmentos em um único corte de $100 \mathrm{x}$ 150 x 130); área de ocupação com no mínimo 90 hectares e uma seqüência de ocupação que durou desde o princípio do primeiro milênio a.C. até o século XVI d.C. (Heckenberger et al. 1998). Na mesma área de pesquisa, ao menos dois outros sítios com dimensões análogas foram também preliminarmente identificados ( $\mathrm{Ne}$ ves e Bartone 1998), mas apenas trabalhos posteriores poderão confirmar essas impressões iniciais e verificar a validade do modelo de Meggers bem como as interpretações dos primeiros cronistas.

A avaliação dessas hipóteses, por sua vez, ajudará a compreender outra questão teórica aberta pela arqueologia amazônica: a determinação da organização política das sociedades pré-coloniais tardias da região. Desde os meados dos anos 80, Roosevelt (1987, 1989, 1991b, 1992) tem afirmado que algumas dessas sociedades teriam sido politicamente organizadas em um padrão do tipo cacicado. Embora tal hipótese já tenha sido proposta anteriormente por Myers (1973), coube novamente a Roosevelt a oportunidade de acesso a dados indisponíveis a pesquisadores durante muitos anos, principalmente na região da foz do Amazonas.

Da mesma maneira que Lathrap e Meggers, Roosevelt (1991a, 1993:265) trabalha com a premissa de que as áreas de várzea proviam condições ecológicas favoráveis para o desenvolvimento da complexidade social na Amazônia pré-colonial. No caso das sociedades de construtores de aterros de Marajó, Roosevelt sugeriu, com base em dados históricos e arqueológicos de suas escavações de Teso dos Bichos, que esta e outras sociedades da várzea amazônica teriam sido cacicadas com as seguintes características comuns: centralização política com territórios grandes, às vezes com dezenas de milhares de metros quadrados; guerra expansionista; organização social hierárquica; tributação; agricultura intensiva e exploração de fauna aquática; sofisticadas cerâmicas polícromas e inciso-ponteadas; incidência de iconografia antropomorfa na decoração dos vasilhames (ver Schaan 1997 para outra interpretação desse fenômeno); comércio extenso; sepultamentos em urnas funerárias; fabricação de ídolos cerâmicos e líticos; grandes adensamentos populacionais, incluindo assentamentos com milhares de indivíduos; arquitetura monumental, incluindo tesos, campos de cultivo elevados, diques e outros tipos de aterros com diferentes funções: controle hidráulico, agricultura, habitação, transporte e defesa (Roosevelt 1992: 71).

Os dados preliminares obtidos por Roosevelt (1991b) em Teso dos Bichos (1991b) aparentemente apóiam esse modelo, apesar de não terem sido completamente publicados. É assim necessário que se espere pelos resultados adicionais para que possa ser devidamente avaliado. Este é o caso, por exemplo, dos materiais ósseos. Os dados disponíveis indicam características interessantes, como deformação fronto-occipital em alguns crânios masculinos; variabilidade na composição 
química do colágeno; baixa incidência de patologias; estatura média superior à dos índios amazônicos contemporâneos (1991b: 58). Roosevelt reconhece, porém, que o tamanho relativamente pequeno das amostras de Marajó e a falta de documentação detalhada permitem apenas algumas observações não conclusivas (1991b: 58).

O mesmo pode ser dito sobre determinação dos padrões de assentamento. Novamente, embora exista evidência de variabilidade nos padrões do uso do espaço em Marajó - um indicador potencial de hierarquia ou especialização econômica os dados sobre esse tema não estão ainda completamente disponíveis (Roosevelt 1991b: 36-7). Um nível de ocupação no Teso dos Bichos revelou mais de vinte vestígios de malocas, orientadas no sentido leste-oeste (Roosevelt 1991b: 37, 333 7). A localização das malocas foi inferida através da evidenciação de fornos - conjuntos de estruturas de barro queimado de formato côncavo, embora sem vestígios de carvões (Roosevelt 1991b: 288-9, e Capítulo 5). Essas estruturas foram interpretadas como fogões com base na comparação com dados etnográficos da Indonésia e do Marajó contemporâneo (Roosevelt 1991b: 290). A ocorrência de malocas foi deduzida pela analogia com as malocas documentadas etnograficamente no noroeste da Amazônia. Conforme as palavras de Roosevelt (1991b: 334-5), no entanto, escavações adicionais serão necessárias para determinar a forma, o tamanho, e a orientação das habitações

Roosevelt (1991b: 289, 341-2) produziu, também com base em analogias etnográficas, estimativas populacionais para essas aldeias de malocas, assumindo uma população de mais ou menos 50 pessoas por maloca, resultando em 1.000 indivíduos por período de ocupação: 50 habitantes em 20 malocas. Tais estimativas são plausíveis: Prous (1992: 481) chegou a uma estimativa de 2.000 habitantes para o conjunto de aterros de Camutins, também localizado na Ilha de Marajó, baseado em uma nova análise dos dados primários providos por Meggers e Evans (1957). Grandes agre- gados populacionais não constituem necessariamente uma condição prévia para o desenvolvimento de hierarquias. Dados populacionais para, por exemplo, o Brasil central e oriental indicam também assentamentos com várias centenas de habitantes Há registros, para os Tupinambá, de aldeias com uma média de quatro a oito malocas e população de 500 até $2.000 \mathrm{ou}$ 3.000 pessoas por aldeia (Fausto 1992: 384), sem, no entanto, evidências de uma organização política do tipo cacicado.

A avaliação do status político das sociedades marajoaras também depende da compreensão das atividades ligadas à construção dos aterros. Dada a duração da fase Marajoara - mais ou menos 900 anos, de 400 a 1300 d.C. - é importante que se estabeleça se os montículos foram construídos em episódios a curto ou longo prazo.

Roosevelt (1991b: 333) mostrou que, durante as ocupações relacionadas à subfase Pacoval, a construção dos aterros foi realizada para a retenção de paredes ou o apoio de plataformas. Não está claro, assim, se foram estruturas monumentais construídas à custa de grande mobilização de trabalho em intervalos de tempo relativamente curtos. Dada a duração da subfase Pacoval, é plausível sugerir que a construção de aterros era apenas uma atividade regular para impedir o desmoronamento dessas estruturas (Roosevelt 1991b: 246).

A presença de aterros não deve ser vista isoladamente como correlata a um tipo de organização política hierárquica ou centralizada, já que é necessário que as formas de mobilização de trabalho envolvidas na construção dessas estruturas sejam compreendidas (Kristiansen 1991: 22). Alguns dos sambaquis de Santa Catarina, por exemplo, como Garopaba do Sul, tinham dimensões estimadas em 400 x 100 × 30 m (Prous 1992: 207), mas ninguém os considerou relacionados a cacicados, pelo menos até o momento.

Desse modo, os dados arqueológicos atualmente disponíveis para o leste de Marajó não indicam de maneira clara que o 
registro arqueológico da fase Marajoara corresponda a cacicados. O conceito de cacicado tem uma aplicação ainda difícil na Amazônia devido à grande diversidade de formações sociais que ali existiam antes da conquista, bem como à base ainda incompleta de dados. A simples correlação de elementos materiais - como a construção de aterros ou arquitetura complexa com formações sociais do passado pode ser muito rígida e incapaz de explicar a dinâmica dessas sociedades (Drennan 1995). Assim sendo, são necessários estudos com perspectivas diacrônicas de longa duração antes que se resolva aplicar rótulos do tipo "tribo" ou "cacicado".

A hipótese geral de Roosevelt sobre as transformações políticas trazidas pela conquista tem o mérito de estimular pesquisas com o objetivo de avaliar, sob uma perspectiva arqueológica, o impacto do contato em diferentes áreas da Amazônia, já que a conquista não foi um processo uniforme, mas a combinação de ações de agentes com diferentes interesses em diferentes períodos (Myers 1990). Do mesmo modo, esta hipótese geral precisa incorporar os tipos variados de resistência ou ajustes encontrados pelos índios amazônicos para lidar com o avanço europeu.

Assim, no alto Rio Negro, Neves (1998) não encontrou diferenças significativas entre o tamanho e a densidade dos sítios arqueológicos pré-coloniais e as malocas descritas na etnografia até meados do século XX, ao contrário do alto Xingu onde Heckenberger (1966) encontrou uma diferença significativa entre os registros arqueológico e etnográfico.

\section{CONCLUSÕES}

Os temas aqui discutidos indicam que os esquemas explicativos disponíveis para a arqueologia amazônica são, de diferentes maneiras, ainda bastante influenciados pelo paradigma teórico apresentado por Steward e seus colaboradores no Handbook of South
American Indians. Tal influência pode ser percebida, por exemplo, nas repetidas tentativas de procurar fatores únicos, normalmente variáveis ambientais, para explicar processos sociais no passado pré-colonial amazônico.

Algumas das evidências acima discutidas apontam, por outro lado, para diferentes bases para uma arqueologia amazônica mais independente da herança do Handbook. Primeiramente, há a constatação de que as formações sociais amazônicas pretéritas e contemporâneas têm uma matriz regional que inclui - pelo menos como é atualmente conhecido - a circulação das pessoas e bens por áreas às vezes extensas, incluindo uma razoável diversidade lingüística, econômica e ecológica. Tais sistemas regionais não devem no entanto corresponder a organizações políticas do tipo cacicado.

Em segundo lugar, um quadro ecológico mais complexo tem emergido para a Amazônia durante os últimos anos (Moran 1993). Há, assim, evidências de uma diversidade ecológica maior que o previamente considerado. As conseqüências são importantes para a arqueologia, porque, como vimos, modelos explicativos na arqueologia amazônica estiveram sistematicamente baseados em premissas ecológicas. Deve-se considerar também os trabalhos recentes em ecologia histórica (Balée 1989, 1994, 1995; Smith 1980), que indicam que as sociedades indígenas da Amazônia não são vítimas passivas de supostas limitações ambientais, mas que, ao contrário, exerceram uma influência criativa e modificadora sobre o meio ambiente. Conseqüentemente, pode-se supor que o que é visto atualmente como floresta "primitiva" na Amazônia seja de fato paisagens culturais resultantes do manejo humano milenar. Tais fatores têm implicações importantes porque apresentam um quadro substancialmente diferente do "modelo padrão" ortodoxo para as terras baixas da América do Sul (Viveiros de Castro 1996), ao mesmo tempo em que colocam novas questões para a arqueologia brasileira. 


\section{REFERÊNCIAS BIBLIOGRÁFICAS}

Adams, C. 1994 As florestas virgens manejadas. Boletim do Museu Paraense Emilio Goeldi, série Antropologia, 10(1): 3-20.

Adams, J. e Faure, H. 1997 Preliminary Vegetation Maps of the World since the Last Glacial Maximum: An Aid to Archaeological Understanding. Journal of Archaeological Science, 24: 623-47.

Arvelo-Jiménez, N. e Biord, H. 1994 The Impact of Conquest on Contemporary Indigenous Peoples of the Guiana Shield: The System of Orinoco Regional Interdependence. In: Roosevelt, A. (ed.), Amazonian Indians from prehistory to the present: anhropological perspectives, pp. 55-78. University of Arizona Press, Tucson.

Balée, W. 1994 Footprints of the Forest. Ka'apor Ethnobotany - the Historical Ecology of Plant Utilization by an Amazonian People. Columbia University Press, New York.

1995 Historical Ecology of Amazonia. In: Sponsel, L. (ed.), Indigenous peoples and the future of Amazonia: an ecological anthropology of an endangered world, pp. 97-110. University of Arizona Press, Tucson.

Balée, W. e Moore D. 1994 Language, Culture, and Environment: Tupi-Guaraní Plant Names Over Time, In: Roosevelt, A. (ed.), Amazonian Indians from prehistory to the present: anhropological perspectives, pp. 363-80. University of Arizona Press, Tucson.

Barbosa Rodrigues, J. 18880 Muiraquitã. Tipografia do Amazonas, Manaus.

Barreto, M. 1992 História da pesquisa arqueológica no Museu Paraense Emílio Goeldi. Boletim do Museu Paraense Emilio Goeldi, nova série, Antropologia, 8, 2: 203-94.

Basso, E. 1973 The Kalapalo Indians of Central Brazil. Holt, Rinehart and Winston, New York.

Beckerman, S. 1979 The abundance of protein in Amazonia: A reply to Gross. American Anthropologist, 81: 533-60.

Biord-Castillo, H. 1985 El contexto multilingüe del sistema de interdependencia regional del Orinoco. Antropologica, 63-4: 83-101.

Blench, R. e Spriggs, M. (eds.) 1997 Archaeology and Language I. Theoretical and Methodological Orientations. Routledge, London.

Brochado, J. 1980 The social ecology of the Marajoara chiefdom. Master's thesis, University of Illinois.

. 1984 An Ecological Model of the Spread of Pottery and Agriculture into Eastern South America. Ph.D. Dissertation, University of Illinois.

Brochado, J. e Lathrap, D. 1982 Chronologies in the New World: Amazonia (manuscrito não publicado).

Butt-Colson, A. 1973 Inter-tribal trade in the Guiana Highlands. Antropologica, 34: 1-69.

Carneiro, R. 1957 Subsistence in Social Structure: An Ecological Study of the Kuikuru Indians. Ph.D. Dissertation, Department of Anthropology, University of Michigan. . 1970 A Theory of the Origin of the State. Science, 169: 733-8.

1971 Review of "The Upper Amazon". American Journal of Archaeology, 75: 237-9.

Colinvaux, P. 1987 Amazon diversity in light of the paleoecological record. Quaternary Science Reviews, 6: 93-1 14.

DeBoer, W. e Lathrap D. 1979 The making and breaking of Shipibo-Conibo ceramics. In: Kramer, C. (ed.), Ethnoarchaeology: implications of ethnography for archaeology, pp. 102-38. Columbia University Press, New York.

DeBoer, W., Kintigh, K. e Rostoker, A. 1996 Ceramic seriation and site reoccupation in Lowland South America. Latin American Antiquity, 7(3): 263-78.

Denevan, W. 1966 The Aboriginal Cultural Geography of the Llanos de Mojos of Bolivia. University of California Press, Berkeley.

. 1992a The Pristine Myth: The Landscape of the Americas in 1492. Annals of the Association of American Geographers, 82 (3): 369-85.

1992b Native American Population in 1492: Recent Research and Revised Hemispheric Estimate. In: Denevan, W. (ed.), The Native Population of the Americas in 1492, second edition, pp. xvii-xxxviii. University of Wisconsin Press, Madison.

1996 A Bluff Model of Riverine Settlement in Prehistoric Amazonia. Annals of the Association of American Geographers, 86(4): 654-81.

Descola, P. 1986 La Nature Domestique: Symbolisme et praxis dans l'écologie des Achuar. Foundation SingerPolignac/Edition de la Maison des sciences de l'homme, Paris.

1994 Homeostasis as a Cultural System: the Jivaro case. In: Roosevelt, A. (ed.), Amazonian Indians from prehistory to the present: anthropological perspectives, pp. 203-24. University of Arizona Press, Tucson. Dillehay, T.; Ardila, G.; Politis, G.; e Beltrão, M. 1992 Earliest Hunters and Gatherers of South America. Journal of 
World Prehistory, 6(2): 145-204.

Drennan, R. 1995 Chiefdoms in Northern South America. Journal of World Prehistory, 9(3): 301-40.

Dreyfuss, S. 1983-84 Historical and political anthropological interconnections: the multi-linguistic indigenous polity of the 'Carib' islands and the mainland coast from the 16th to the 18th century. Antropologica, 59-62: 39-55.

1993 0s Empreendimentos Coloniais e os Espaços Políticos Indígenas no Interior da Guiana Ocidental (entre o Orenoco e o Corentino) de 1613 a 1796. In: Viveiros de Castro, E.; Carneiro da Cunha, M. (eds.), Amazônia: Etnologia e História Indígena, pp. 19-41. Núcleo de História Indígena e Indigenismo - USP, São Paulo.

Eden, M.; Bray, W.; Herrera, L. e C. McEwan, L. 1984 Terra Preta soils and their archaeological context in the Caquetá Basin of Southeast Colombia. American Antiquity, 49(1): 125-40.

Erickson, C. 1995 Archaeological methods for the study of ancient landscapes of the Llanos de Mojos in the Bolivian Amazon. In: Stahl, P. (ed.), Archaeology in the lowland American Tropics: current analytical methods and applications, pp. 66-95. Cambridge University Press, Cambridge.

Erikson, P. 1992 Uma singular pluralidade: a etno-história pano. In: Carneiro da Cunha, M. (ed.), História dos Índios no Brasil, pp. 239-52. Companhia das Letras/Fapesp/SMC, São Paulo.

Evans, C. 1971 Review of "The Upper Amazon". American Anthropologist, 73: 1.414-6.

Evans, C. e Meggers, B. 1968 Archaeological Investigations on the Rio Napo, Eatern Ecuador, Smithsonian Contributions to Anthropology, vol. 6. Smithsonian Institution Press, Washington.

Falesi, I. 1974 Soils of the Brazilian Amazon. In: Wagley, C. (ed.), Man in the Amazon, pp. 201-29. University Press of Florida, Gainesville.

Farage, N. 1991 As Muralhas dos Sertões. Os povos indígenas no Rio Branco e a colonização. Paz e Terra, Rio de Janeiro.

Fausto, C. 1992 Fragmentos de história e cultura Tupinambá: da etnologia como instrumento crítico de conhecimento etno-histórico. In:Carneiro da Cunha, M. (ed.), História dos Índios no Brasil, pp. 381-96. Companhia das Letras/ Fapesp/SMC, São Paulo.

Feinman, G. e Neitzel, J. 1984 Too Many Types: An Overview of Sedentary Prestate Societies in the Americas. Advances in Archaeological Method and Theory, vol. 7.

Flowers, N. 1994 Subsistence Strategy, Social Organization, and Warfare in Central Brazil in the Context of European Penetration. In: Roosevelt, A. (ed.), Amazonian Indians from prehistory to the present: anthropological perspectives, pp. 249-69. University of Arizona Press, Tucson.

Galvão, E. 1960 Áreas culturais indígenas do Brasil: 1900/1959. Boletim do Museu Paraense Emilio Goeldi, NS, Antropologia, 8.

Guapindaia, V. 1993 Fontes Históricas e Arqueológicas sobre os Tapajó: A Coleção "Frederico Barata" do Museu Paraense Emílio Goeldi. Dissertação de mestrado, Universidade Federal de Pernambuco.

Hartt, C. 1885 Contribuições para a etnologia do vale do Amazonas. Arquivos do Museu Nacional, vol. 6.

Headland, T. e Bailey, R. 1991 Introduction: Have Hunter-Gatherers Ever Lived in Tropical Rain Forest Independently of Agriculture? Human Ecology, 19, 2.

Heckenberger, M. 1996 War and Piece at the Shadow of Empire: sociopolitical change in the Upper Xingu of Southeastern Amazonia, AD 1250-2000. PhD. Dissertation, University of Pittsburgh.

Heckenberger, M.; Neves, E. e Petersen, J. 1998 De Onde vêm os modelos?: a arqueologia da origem dos Tupi e Guarani. Revista de Antropologia/USP.

Herrera, L.; Bray, W. e McEwan, C. 1980-1981 Datos Sobre la Arqueología de Araracuara (Comisaría del Amazonas Colombia). Revista Colombiana de Antropologia, XXIII: 185-251.

Herrera, L.; Cavelier, I.; Rodríguez, C. e Mora, S. 1992 The technical transformation of an agricultural system in the Colombian Amazon. World Archaeology, 24(1): 98-113.

Hilbert, P. 1968 Archäologische Untersuchungen am Mittlern Amazonas. Dietrich Reimer Verlag, Berlin.

Hoopes, J. 1994 Ford Revisited: A Critical Review of the Chronology and Relationships of the Earliest Ceramic Complexes in the New World, 6,000-1,500 BC. Journal of World Prehistory, 8, 1: 1-49.

Jackson, J. 1983 The Fish People: Linguistic and Exogamy and Tukanoan Identity in Northwest Amazonia. Cambridge University Press, Cambridge.

Kästner, K.P. 1992 Historisch-ethnographische Klassification der Stämme des Ucayali-Beckens (Ost-Peru). IKO Verlag, Frankfurt.

Kern, D. 1996 Geoquímica e Pedogeoquímica de Sítios Arqueólogicos com terra Preta na Floresta Nacional de 
Caxiuanã (Portel-Pará). Dissertação de Doutorado, Universidade Federal do Pará.

Kirch, P. e Green, R. 1987 History, Phylogeny and Evolution in Polynesia. Current Anthropology 28: 421-46.

Kristiansen, K. 1991 Chiefdoms, states, and systems of social evolution. In: Earle, T. (ed.), Chiefdoms: Power,

Economy, and Ideology, pp. 16-43. Cambridge University Press, Cambridge.

Lamb, J. e Vargas, P. 1995 The Many Contexts of Early Valdivia Ceramics. In: Barnett, W e Hoopes J. (eds.), The

Emergence of Pottery. Technology and Innovation in Ancient Societies, pp. 157-68. Smithsonian Institution Press, Washington.

Lathrap, D. 1968a Aboriginal occupation and changes in river channel on the Central Ucayali, Peru. American Antiquity 33(1): 62-79.

. 1968b The "Hunting" Economies of the Tropical Forest Zone of South America. In: Lee, R. e DeVore,

I. (eds.), Man the Hunter, pp. 23-9. Aldine, Chicago.

1970a The Upper Amazon. Thames and Hudson, London.

. 1970b Review of Archäologische Untersuchungen am Mittlern Amazonas, by P. Hilbert. American Antiquity 35(4): 499-501.

1973a Summary or Model Building: How Does One Achieve a Meaningful Overview of a Continent's Prehistory. American Anthropologist, 75: 1.755-67.

$1973 \mathrm{~b}$ The antiquity and importance of long-distance trade relationships in the moist tropics of PreColumbian South America. World Archaeology, 5(2): 170-85.

1973c Gifts of the cayman: some thoughts on the subsistence basis of Chavín. In: Lathrap, D. e

Douglas, J. (eds.), Variation in Anthropology, pp. 91-105. Illinois Archaeological Survey, Urbana.

1974 The Moist Tropics, the Arid Lands, and the Appearance of Great Art Styles in the New World. In:

King, M. e Traylor, I. (eds.), Art and Environment in Native North America, pp. 115-58. Texas Tech University

Museum, Lubbock.

1977 Our Father the Cayman, Our Mother the Gourd: Spinden Revisited or a Unitary Model for the

Emergence of Agriculture in the New World. In: Reed, C. (ed.), Origins of Agriculture, pp. 115-58. The Hague, Mouton.

Lathrap, D. e Oliver, J. 1987 Agüerito: el complejo policromo mas antiguo de America en la confluencia del Apure y el Orinoco (Venezuela). Interciencia, 12: 274-89.

Lathrap, D., Marcos, J. e Zeidler, J. 1977 Real Alto: An Ancient Ceremonial Center. Archaeology, 30(1): 2-13.

Lathrap, D., Gebhart-Sayer, A. e Mester, A. 1985 The Roots of the Shipibo Art Style: Three Waves on Imiriacocha or There Were "Incas" Before the Incas. Journal of Latin American Lore, 11: 31-119.

Linné, S. 1928 Les recherches archéologiques de Nimuendajú au Brésil. Journal de la Société des Américanistes de Paris 20: 71-92.

Lowie, R. 1948 The Tropical Forests: An Introduction. In: Steward, J. (ed.), Handbook of South American Indians, vol. 3, pp. 1-56. Bureau of American Ethnology, Smithsonian Institution, Bulletin 143, Washington, DC.

Magalhães, M. 1994 Arqueologia de Carajás: A presença pré-histórica do homen na Amazônia. Companhia Vale do Rio Doce, Rio de Janeiro.

Meggers, B. 1954 Environmental Limitation on the Development of Culture. American Anthropologist, 56: 801-23. 1971 Amazonia: Man and Culture in a Counterfeit Paradise. Aldine, Chicago.

1977 Vegetational fluctuation and prehistoric cultural

adaptations in Amazonia: some tentative correlations. World Archaeology 8(3): 287-303.

1979 Climatic Oscillation as a Factor in the Prehistory of Amazonia. American Antiquity, 44(2): 252-66. 1982 Archaeological and Ethnographic Evidence Compatible with the Model of Forest Fragmentation.

In: Prance, G. (ed.), Biological Diversification in the Tropics, pp: 483-96. Columbia University Press, New York. 1985 Advances in Brazilian Archaeology, 1935-1985. American Antiquity, 50 (2): 364-73.

. 1987 The Early History of Man in Amazonia. In: Whitemore, T. e Prance, G. (eds.), Biogeography and

Quaternary History in Tropical America, pp. 151-74. Clarendon Press, Oxford.

1990 Reconstruç̃o do Comportamento Locacional Pré-Histórico na Amazônia. Boletim do Museu

Paraense Emilio Goeldi, NS, Antropologia, vol.6 (2): 183-203.

. 1991 Cultural Evolution in Amazonia. In: Rambo, A. e Gillogly, K. (eds.), Profiles in Cultural Evolution.

Papers from a Conference in Honor of Elman Service, pp. 191-216. Museum of Anthropology, University of

Michigan, Ann Arbor.

1992a Cuarenta años de colaboración. In: Meggers, B. (ed.), Prehistoria Sudamericana: Nuevas 
Perspectivas, pp. 13-26. Taraxacum, Washington, DC.

. 1992b Prehistoric Population Density in the Amazon Basin. In: Verano, J. e Ubelaker, D. (eds.),

Disease and Demography in the Americas, pp. 197-205. Smithsonian Institution Press, Washington, DC.

.1993-95 Amazonia on the Eve of European Contact: Ethnohistorical, Ecological, and Anthropological

perspectives. Revista de Arqueología Americana, 8: 91-115.

1995 Judging the Future by the Past: The Impact of Environmental Instability on Prehistoric

Amazonian Populations. In: Sponsel, L. (ed.), Indigenous peoples and the future of Amazonia: an ecological

anthropology of an endangered world, pp. 15-43. University of Arizona Press, Tucson.

Meggers, B. e Evans, C. 1957 Archaeological Investigations at the Mouth of the Amazon. Bureau of American

Ethnology, Bulletin no 167, Washington.

. 1961 An Experimental Formulation of Horizon Styles in the Tropical Forest of South America, In:

Lothrop, S. (ed.), Essays in Pre-Columbian Art and Archaeology, pp.372-88. Harvard University Press, Cambridge.

1970 Como Interpretar a Linguagem da Cerâmica: Manual para Arqueólogos. Smithsonian Institution,

Washington, DC.

1973 A reconstituição da pré-história amazônica, algumas considerações teóricas. Publicações Avulsas

do Museu Paraense Emilio Goeldi, no 20: 51-69.

1979 An Experimental Reconstruction of Tarumã Village Succession and Some Implications. In:

Margolis, M. e Carter, W. (eds.), Brazil: Anthropological perspectives, pp. 39- 60. Columbia University Press, New

York.

. 1980 Un Método Cerámico para el Reconocimiento de Comunidades Pre-Históricas. Boletín del Museu del Hombre Dominicano, Año IX, 14: 57-73.

. 1983 Lowland South America and the Antilles, In: Jennings, J. (ed.), Ancient South Americans, pp.

287-335. W. H. Freeman, San Francisco.

Meggers, B. e Danon, J. 1988 Identification and Implications of a Hiatus in the Archaeological Sequence on Marajó

Island, Brazil. Journal of the Washington Academy of Sciences, 78(3): 245-53.

Meggers, B.; Evans, C. e Estrada, E. 1965 Early Formative period of coastal Ecuador: the Valdivia and Machalilla phases. Smithsonian Contributions to Anthropology, vol. 1.

Meggers, B.; Dias, 0.; Miller, E. e Perota, C. 1988 Implications of archaeological distributions in Amazonia.

In:Vanzolini, P. e Heyer, W. (eds.), Proceedings of a Workshop on Neotropical Distribution Patterns, pp. 275-94.

Academia Brasileira de Ciências, Rio de Janeiro.

Mendonça de Souza, A. 1991 História da Arqueologia Brasileira. Pesquisas (Antropologia), 46.

Migliazza, E. 1982 Linguistic Prehistory and the Refuge Model in Amazonia. In: Prance, G. (ed.), Biological

Diversification in the Tropics, pp: 497-519. Columbia University Press, New York.

Miller, E. et al. 1992 Arqueologia nos empreendimentos hidrelétricos da Eletronorte; resultados preliminares. Eletronorte, Brasília.

Mora, S.; Herrera, L.; Cavelier, I. e Rodríguez, C. 1991 Cultivars, Anthropic Soils and Stability: a preliminary report of archaeological research in Araracuara, Colombian Amazon. Pittsburgh, University of Pittsburgh Latin American Archaeology Reports, ํo 2.

Moran, E. 1993 Through Amazonian Eyes. University of lowa Press, lowa City.

Morey, R. e Morey, N. 1975 Relaciones comerciales en el pasado en los llanos de Colombia y Venezuela. Montalban n. 4: 533-64.

Myers, T. 1973 Toward the Reconstruction of Prehistoric Community Patterns in the Amazon Basin. In: Lathrap, D. e Douglas, J. (eds.), Variation in Anthropology, pp. 233-52. Illinois Archaeological Survey, Urbana.

. 1981 Aboriginal Trade Networks in Amazonia. In: Francis, P.; Duke, P. e Kense, F. (eds.), Networks of the Past, pp. 19-30. University of Calgary Archaeological Association, Calgary.

. 1990 Sarayacu: Ethnohistorical and Archaeological Investigations of a nineteenth-century Franciscan

Mission in the Peruvian Montaña. University of Nebraska Studies, new series, ํo 68.

1992 Agricultural limitations of the Amazon in theory and practice. World Archaeology, 24(1): 82-97.

Netto, L. 1885 Investigações sobre a Arqueologia Brasileira. Arquivos do Museu Nacional, vol. 6.

Neves, E. 1995a Village Fissionning in Amazonia: A Critique of Monocausal Determinism. Revista do Museu de Arqueologia e Etnologia da Universidade de São Paulo, IV.

. 1995b Os índios antes de Cabral: Arqueologia e História Indígena no Brasil. In: Lopes da Silva, A. e

Grupioni, L. (eds.), A temática indígena na escola, pp. 171-92. MEC/Mari/Unesco, Brasília. 
1997 Dados sobre a arqueologia do Rio Negro. Trabalho apresentado no IX Congresso da Sociedade de Arqueologia Brasileira, Rio de Janeiro.

1998 Paths in Dark Waters: Archaeology as Indigenous History in the Upper Rio Negro Basin,

Northwest Amazon. Dissertação de Doutorado, Department of Anthropology, Indiana University.

Neves, E. e Bartone, R. 1998 Preliminary results of an archaeological survey in the central Amazon. Trabalho apresentado na 63a Reunião da Society for American Archaeology, Seattle.

Neves, W. 1989 Teorias de determinismo ecológico na Amazônia: um caso de marginalidade da comunidade científica nacional. In: Neves, W. (ed.), Biologia e Ecologia Humana na Amazônia: Avaliação e Perspectivas, pp. 59-76. Museu Paraense Emilio Goeldi, Belém.

Nimuendajú, C. 1982 Mapa Etno-Histórico do Brasil e Regiões Adjacentes. Instituto Brasileiro de Geografia e Estatísitica, Brasília.

Noble, G. K. 1965 Proto-Arawakan and its descendants. Indiana University Publications in Anthropology and Linguistics, 38. Indiana University, Bloomington.

Noelli, F. 1996 As hipóteses sobre o centro de origem e rotas de expansão dos Tupi. Revista de Antropologia/USP $39(2): 7-53$.

Nordenskiöld, E. 1929 The American Indian as an Inventor (The Huxley Memorial Lecture for 1929). The Journal of the Royal Anthropological Institute of Great Britain and Ireland, vol. LIX: 273-309.

1930 L'archéologie du bassin de l'Amazone. Les Éditions G. van Oest, Paris.

Oliveira, A. 1988 A Amazônia: modificações sociais e culturais decorrentes do processo de ocupação humana (séc. XVII ao XX). Boletim do Museu Paraense Emílio Goeldi, NS, Antropoplogia, 4: 65-115.

Oliver, J. 1989 The Archaeological, linguistic and etnohistorical evidence for the expansion of Arawakan into Northwestern Venezuela and Northeastern Colombia. Dissertação de Doutorado, Department of Anthropology, University of Illinois.

1991 Donald Lathrap: approaches and contributions to New World archaeology. Antropologica, 75 6: 5-60.

Pabst, E. 1991 Critérios de distinção entre terra preta e latossolo na região de Belterra e os seus significados para a discussão pedogenética. Boletim do Museu Parasense Emilio Goeldi, NS, Antropologia, 7(1): 5-19.

Perota, C. e Botelho, W. 1992 Les "Sambaquis" de Guará et des variations climatiques pendant I'Holocene. In: Prost, M. (ed.), Évolution des Littoraux de Guyane et de la Zone Caraïbe Méridionale Pendant le Quaternaire. Editions de I'ORSTOM, Paris.

Politis, G. 1996 Moving to produce: Nukak mobility and settlement patterns in Amazonia. World Archaeology, 27(3): 492-511.

1997 Nukak. Instituto Amazónico de Investigaciones Científicas - SINCHI, Bogotá.

Porro, A. 1993 As Crônicas do Rio Amazonas. Notas etno-históricas sobre as antigas populações indígenas da Amazônia. Vozes, Petrópolis.

1994 Social Organization and Political Power in the Amazon Floodplain: The Ethnohistorical Sources.

In: Roosevelt, A. (ed.), Amazonian Indians from prehistory to the present: anthropological perspectives, pp. 79-

94. University of Arizona Press, Tucson.

. 19960 Povo das Águas: Ensaios de Etno-história Amazônica. Vozes, Petrópolis.

Posey, D. 1986 Manejo de Floresta Secundária, Capoeiras, Campos e Cerrados (Kayapó). In: Ribeiro, B. (coord.), Suma Etnológica Brasileira, Vol. I, Etnobiologia, pp. 173-85. Vozes/Finep, Petrópolis.

Prous, A. 1992 Arqueologia Brasileira. Editora da Universidade de Brasília, Brasília.

. 1995 Archaeological analysis of the oldest settlements in the Americas. Brazilian Journal of Genetics,

(18) 4: 689-99

Raymond, J. S. 1995 From potsherds to pots: a first step in constructing cultural context from tropical forest archaeology. In: Stahl, P. (ed.), Archaeology in the lowland American Tropics: current analytical methods and applications, pp. 224-42. Cambridge University Press, Cambridge.

Raymond, J. S.; Oyuela-Caycedo, A. e Carmichael, P. 1994 Una comparación de las tecnologías de la ceámica temprana de Ecuador y Colombia. In: Shimada, I. (ed.), Tecnología y Organización de la Producción Cerámica Prehispanica en los Andes. Pontificia Universidad Católica del Peru, Fondo Editorial, Lima.

Reichel-Dolmatoff, G. 1971 Amazonian Cosmos. University of Chicago Press, Chicago. 1976 Cosmology as Ecological Analysis: A view from the Rain Forest. Man 1 1,3: 307-18.

Rindos, D. 1984 The Origins of Agriculture. Academic Press, New York. 
Rodrigues, A. 1985 Evidence for Tupi-Carib Relationships. In: Klein, H. e Stark, L. (eds.), South American languages: Retrospect and prospect, pp. 371-404. University of Texas Press, Austin.

1986 Línguas Brasileiras: Para o conhecimento das línguas indígenas. Edições Loyola, São Paulo.

Roosevelt, A. 1980 Parmana: Prehistoric maize and manioc subsistence along the Amazon and Orinoco. Academic Press, New York.

. 1987 Chiefdoms in the Amazon and Orinoco. In: Drennan, R. e Uribe, C. (eds.), Chiefdoms in the Americas, pp. 153-85. University Press of America, Lanham.

1989 Resource management in Amazonia before the Conquest. Advances in Economic Botany 7: 30-62.

. 1991 a Determinismo ecológico na interpretação do desenvolvimento social indígena da Amazônia. In:

Neves, W. (ed.), Origens, Adaptações e Diversidade Biológica do Homem Nativo da Amazônia, pp. 103-41.

Museu Paraense Emílio Goeldi, Belém.

.1991b Moundbuilders of the Amazon: Geophysical Archaeology on Marajó Island, Brazil. Academic

Press, San Diego.

1992 Arqueologia Amazônica. In: Carneiro da Cunha, M. (org.), História dos Índios no Brasil, pp. 53-

86. Companhia das Letras/Fapesp/SMC, São Paulo.

. 1993 The Rise and Fall of the Amazonian Chiefdoms. L'Homme, 126-8, XXXIII (2-4): 255-82.

1994 Amazonian Anthropology: Strategy for a New Synthesis, In: Roosevelt, A. (ed.), Amazonian

Indians from prehistory to the present: anthropological perspectives, pp. 1-29. University of Arizona Press, Tucson.

1995 Early Pottery in the Amazon. Twenty Years of Scholarly Obscurity. In: Barnett, W. e Hoopes, J.

(eds.), The Emergence of Pottery. Technology and Innovation in Ancient Societies, pp. 115-31. Smithsonian

Institution Press, Washington.

Roosevelt, A. (ed.) 1994 Amazonian Indians from prehistory to the present: anthropological perspectives. University of Arizona Press, Tucson.

Roosevelt, A. et al. 1991 Eighth Millennium Pottery from a Prehistoric Shell Midden in the Brazilian Amazon. Science 254: 1.621-4.

1996 Paleoindian Cave Dwellers in the Amazon: The Peopling of the Americas. Science, 272: 373-84.

Rostáin, S. 1991 Les Champs Surlevés Amérindiens de la Guyane. Cayenne, Centre Orstom de Cayenne.

Rouse, I. 1953 The circum-Caribbean theory, an archaeological test. American Anthropologist55 (2): 188-200.

. 1985 Arawakan phylogeny, Caribbean chronology, and their implications for the study of population

movement. Antropologica, 63-4: 9-21.

. 1986 Migrations in Prehistory: Inferring Population Movements from Cultural Remains. Yale University

Press, New Haven. New Haven.

1992 The Tainos: rise and decline of the people who greeted Columbus. Yale University Press,

Rouse, I. e Cruxent, J. 1963 Venezuelan Archaeology. Yale University Press, New Haven.

Schaan, D. 1997 A Linguagem Iconográfica da Cerâmica Marajoara. Editora da Pontifícia Universidade Católica do Rio Grande do Sul, Porto Alegre.

Simões, M. 1977 Programa Nacional de Pesquisas Arqueológicas na Bacia Amazônica. Acta Amazonica 7 (3): 297-300. 1981 Coletores-pescadores ceramistas do litoral do Salgado (Pará). Boletim do Museu Paraense Emilio Goeldi, Nova Série, no 78: 1-31.

Simões, M. e Kalkmann, A. 1987 Pesquisas arqueológicas no Médio Rio Negro (Amazonas). Revista de Arqueologia 4(1): 83-116.

Smith, N. 1980 Anthrosols and Human carrying Capacity in Amazonia. Annals of the Association of American Geographers, 70(4): 553-66.

Sorensen Jr., A. 1967 Multilingualism in the Northwest Amazon. American Anthropologist 69: 670-84.

Spencer, C. e Redmond, E. 1992 Prehispanic chiefdoms of the Western Venezuelan Llanos. World Archaeology, 24(1): 134-57.

Stahl, P. e Zeidler, J. 1990 Differential bone-refuse accumulation in food preparation and traffic areas on an early Ecuadorian house floor. Latin American Antiquity 1 (2): 150-69.

Steward, J. 1948 Culture Areas of the Tropical Forests. In: Steward, K. (ed.), Handbook of South American Indians, vol. 3, pp. 883-903. Bureau of American Ethnology, Smithsonian Institution, Bulletin 143, Washington, DC.

Steward, J. e Faron, L. 1959 Native Peoples of South America. McGraw-Hill, New York.

Sweet, D. 1974 A rich realm of nature destroyed: the Middle Amazon valley, 1640-1750. Dissertação de Doutorado, 
University of Wisconsin.

Thomas, D. 1972 An indigenous trade system of Southeast Estado Bolivar, Venezuela, Antropologica, 33: 3-37.

Ugent, D.; Pozorsky, S. e Pozorsky, T. 1986 Archaeological Manioc (Manihot) from Coastal Peru. Economic Botany 40: 78-102.

Urban, G. 1992 A história da cultura brasileira segundo as línguas nativas. In: Carneiro da cunha, M. (org.) , História dos Indios no Brasil, pp. 87-102. Companhia das Letras/Fapesp/SMC, São Paulo.

39, 2: 61-104

1996 On the geographical origins and dispersion of tupian languages. Revista de Antropologia/USP

Van der Merwe, N.; Roosevelt, A. e Vogel, J. 1981 Isotopic evidence for prehistoric subsistence change at Parmana, Venezuela. Nature, vol. 292: 536-8.

Verswijver, G. 1978 Séparations et migrations des Mekrãgnoti, groupe Kayapó du Brésil Central. Bulletin de la Société Suisse des Américanistes, no 42: 47-59.

1992 The Club-Fighters of the Amazon. Warfare among the Kaiapó Indians of Central Brazil.

Rijksuniversitet, Gent.

Viveiros de Castro, E. 1996 Images of Nature and Society in Amazonian Ethnology. Annual Review of Anthropology, 25: 179-200.

Von Martius, C. 19820 Estado de Direito entre os Autóctones do Brasil. Itatiaia/Edusp/Belo Horizonte/São Paulo. Wallace, A. R. 1905 Travels on the Amazon and Rio Negro. Ward, Lock and Co, London.

Whitehead, N. 1990 Carib Ethnic Soldiering in Venezuela, the Guianas, and the Antilles. Ethnohistory, 37, 4: 357-85.

1993 Ethnic Transformation and Historical Discontinuity in Native Amazonia and Guayana, 1500-

1900. L'Homme, 126-8, XXXIII (2-4): 285-305.

1994 The Ancient Amerindian Policies of the Amazon, the Orinoco, and the Atlantic Coast: A

Preliminary Analysis of their Passage from Antiquity to Extinction. In: Roosevelt, A. (ed.), Amazonian Indians from prehistory to the present: anthropological perspectives, pp. 33-53. University of Arizona Press, Tucson.

1995 The Historical Anthropology of Text: the interpretation of Ralegh's Discoverie of Guiana. Current Anthropology, 36(1): 53-74.

Whitten, R. 1979 Comments on the History of Holocene Refugia in the Culture History of Amazonia. American Antiquity, 44(2): 238-51.

Wüst, I. 1994 The Eastern Bororo from an Archaeological Perspective. In: Roosevelt, A. (ed.), Amazonian Indians from prehistory to the present: anthropological perspectives, pp. 315-42. University of Arizona Press, Tucson.

Zucchi, A. 1991 Las migraciones Maipures: diversas líneas de evidencias para la interpretación arqueológica. America Negra, 1: 113-38.

1993 Datos recientes para un nuevo modelo sobre la expansión de los Grupos Maipures del Norte. America Negra, 6: 131-48.

Zucchi, A.; Tarble, K. e Vaz, J. 1984 The Ceramic Sequence and New TL and C-14 Dates for the Agüerito Site of the Middle Orinoco, Venezuela. Journal of Field Archaeology, 11: 155-80. 